\title{
A Protein-Eye View of the In Meso Crystallization Mechanism
}

Leonie van 't Hag, ${ }^{1}$ Liliana de Campo, ${ }^{2}$ Nhiem Tran, ${ }^{3}$ Anna Sokolova, ${ }^{2}$ Raphael Trenker, ${ }^{4,5}$ Matthew E. Call,, 45 Melissa J. Call,, ${ }^{4,5}$ Christopher J. Garvey, ${ }^{2}$ Anna E. Leung, ${ }^{6}$ Tamim A. Darwish, ${ }^{7}$ Anwen Krause-Heuer, ${ }^{7}$ Robert Knott, ${ }^{2}$ Thomas G. Meikle, ${ }^{3}$ Calum J. Drummond, ${ }^{3}$ Raffaele Mezzenga ${ }^{1,8, *}$ and Charlotte E. Conn ${ }^{3,{ }^{*}}$

${ }^{1}$ Department of Health Sciences and Technology, ETH Zurich, CH-8092 Zurich, Switzerland

${ }^{2}$ Australian Centre for Neutron Scattering, Australian Nuclear Science and Technology Organisation (ANSTO), Lucas Heights, New South Wales 2234, Australia

${ }^{3}$ School of Science, College of Science, Engineering and Health, RMIT University, Melbourne, Victoria 3001, Australia

${ }^{4}$ Structural Biology Division, The Walter and Eliza Hall Institute of Medical Research, Parkville, Victoria 3052, Australia

${ }^{5}$ Department of Medical Biology, The University of Melbourne, Parkville, Victoria 3052, Australia

${ }^{6}$ Scientific Activities Division, European Spallation Source ERIC, Lund 224 84, Sweden

${ }^{7}$ National Deuteration Facility, Australian Nuclear Science and Technology Organisation (ANSTO), Lucas Heights, New South Wales 2234, Australia

${ }^{8}$ Department of Materials, ETH Zurich, $\mathrm{CH}-8093$ Zurich, Switzerland

*Corresponding Authors E-mail: charlotte.conn@rmit.edu.au, raffaele.mezzenga@hest.ethz.ch

\section{SUPPORTING INFORMATION}




\section{Supporting Information 1: Synthesis and characterization H-MO and D-MO}

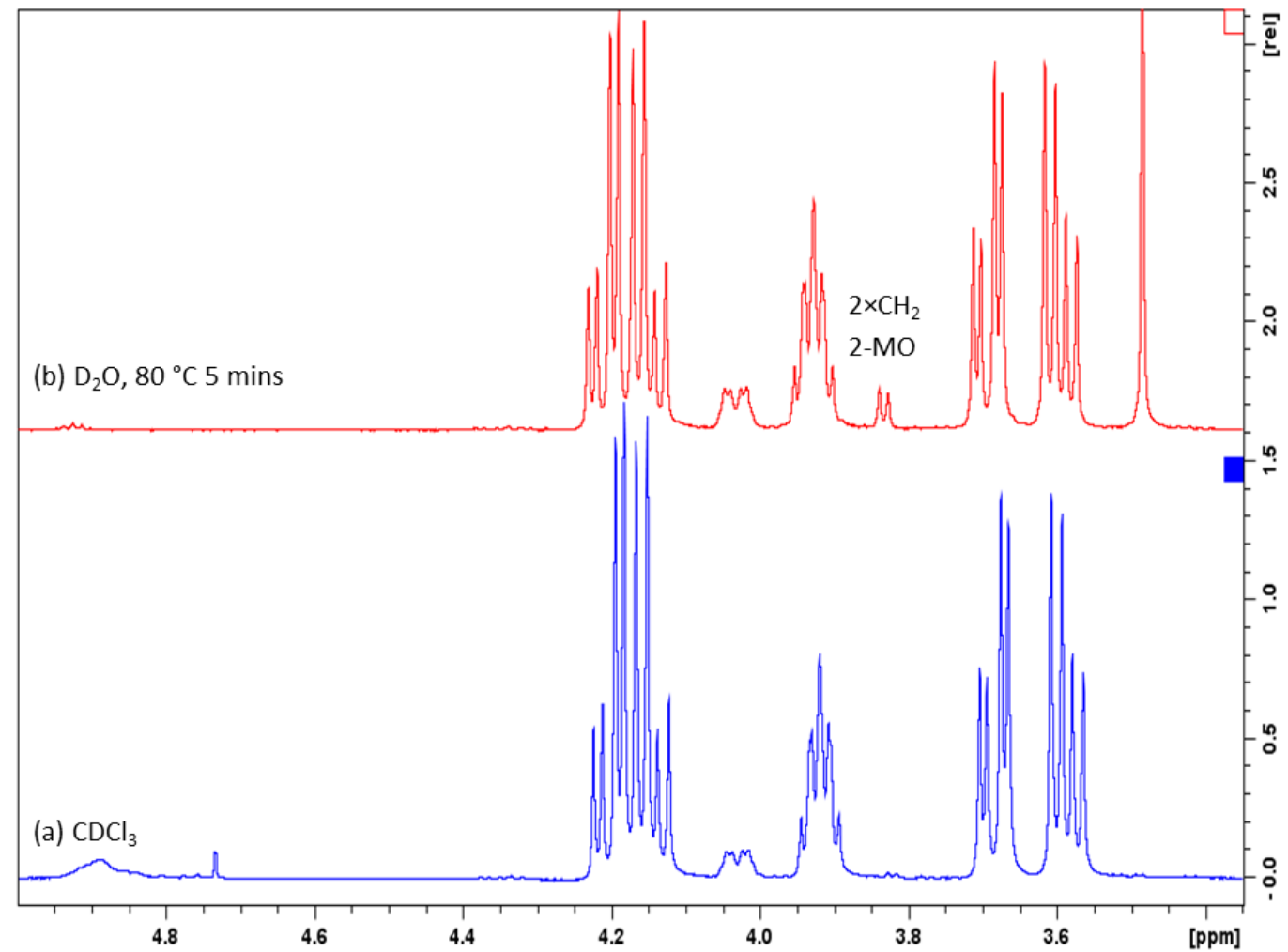

Figure S1.1. ${ }^{1} \mathrm{H}$ NMR spectroscopy showing acyl migration of $\mathrm{H}-\mathrm{MO}$ in $\mathrm{D}_{2} \mathrm{O}$ and at $80{ }^{\circ} \mathrm{C}$.

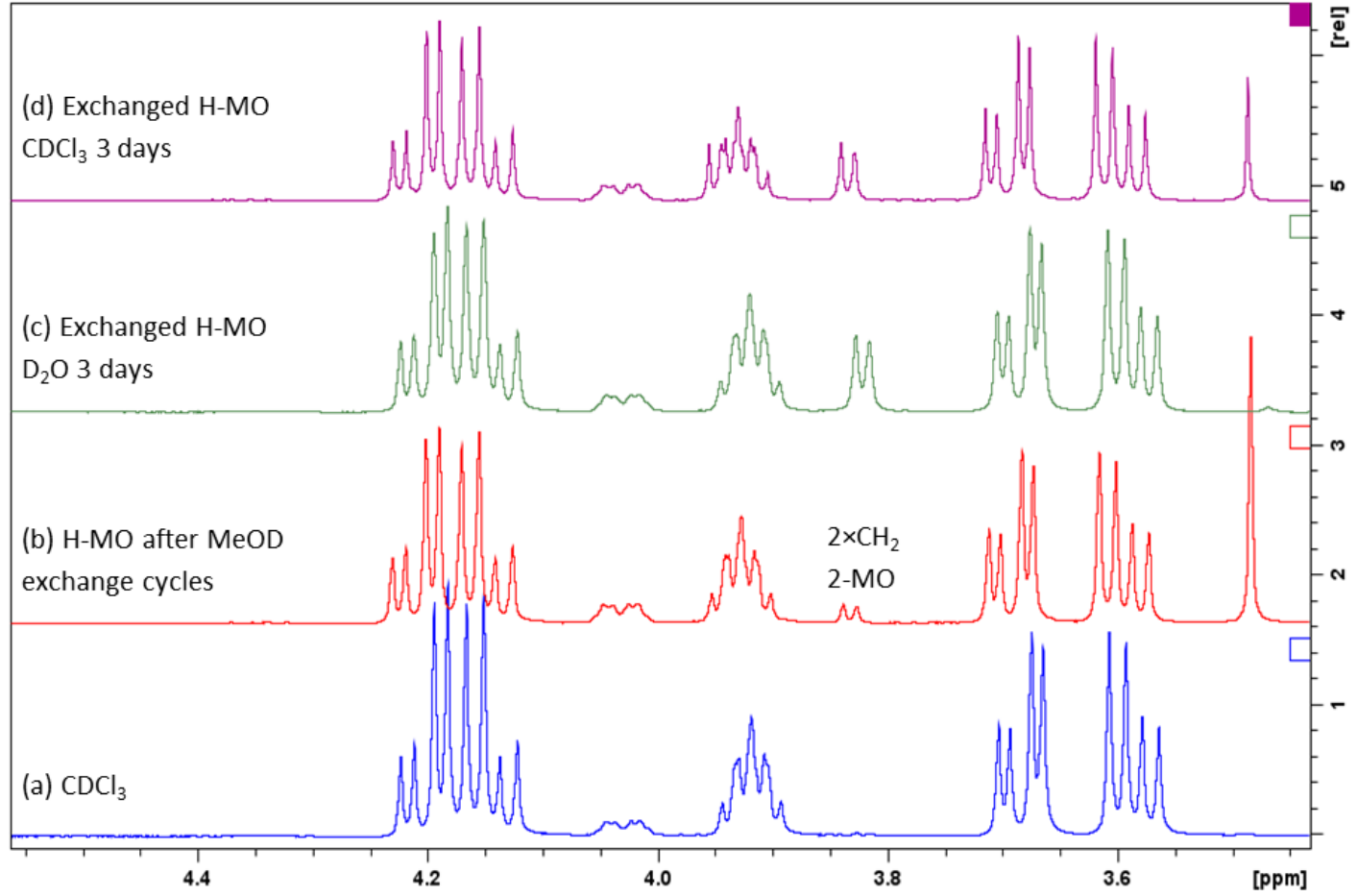

Figure S1.2. ${ }^{1} \mathrm{H}$ NMR spectroscopy showing acyl migration of $\mathrm{H}-\mathrm{MO}$ in $(B) \mathrm{MeOD},(C) \mathrm{D}_{2} \mathrm{O}$ and $(\mathrm{D})$ in $\mathrm{CDCl}_{3}$ at room temperature. 


\section{SYNTHESIS D-MO}

\section{(2,2-Dimethyl-[1,3]-dioxolan-4-yl)-methanol-d 5}<smiles></smiles>

Figure S1.3. Chemical structure (2,2-Dimethyl-[1,3]-dioxolan-4-yl)-methanol- $d_{5}$.

Glycerol- $d_{8}(5.11 \mathrm{~g}, 52.6 \mathrm{mmol})$, anhydrous acetone $(30.0 \mathrm{~mL}, 409 \mathrm{mmol})$, anhydrous pentane $(30 \mathrm{~mL})$ and para-toluenesulfonic acid monohydrate $(140 \mathrm{mg}, 736 \mu \mathrm{mol})$ were added to a flask fitted with a Dean-Stark apparatus and heated to refluxing temperature whilst stirring for $41 \mathrm{~h}$. The mixture was cooled; sodium acetate $(70 \mathrm{mg}, 853 \mu \mathrm{mol})$ was added and the mixture was stirred at room temperature $(\mathrm{rt})$ for $10 \mathrm{~min}$, then filtered and concentrated to afford a pale pink oil which required no further purification (6.74 $\mathrm{g}, 93 \%)$. ${ }^{1} \mathrm{H} \mathrm{NMR}\left(\mathrm{CDCl}_{3}, 400 \mathrm{MHz}\right) \delta 1.36(\mathrm{~s}, 3 \mathrm{H}), 1.43(\mathrm{~s}, 3 \mathrm{H}), 5.67(\mathrm{br} \mathrm{s}, \mathrm{OH}) .{ }^{2} \mathrm{H} \mathrm{NMR}\left(\mathrm{CDCl}_{3}, 61.4 \mathrm{MHz}\right) \delta 3.57(\mathrm{~s})$, $3.71(\mathrm{~s}), 3.78(\mathrm{~s}), 4.02(\mathrm{~s}), 4.22(\mathrm{~s}) .{ }^{13} \mathrm{C} \mathrm{NMR}\left(\mathrm{CDCl}_{3}, 100 \mathrm{MHz}\right) \delta 25.4(\mathrm{~s}), 26.8(\mathrm{~s}), 62.5(\mathrm{~m}), 65.1(\mathrm{~m}), 75.6$ (m), 109.54 (s). MS (ESI+) $\mathrm{m} / z$ calculated for $\mathrm{C}_{6} \mathrm{H}_{7} \mathrm{D}_{5} \mathrm{NaO}_{3}[\mathrm{M}+\mathrm{Na}]^{+}$as 160.1 ; found: 160.1 (90\%). The ${ }^{1} \mathrm{H}$ NMR spectroscopic data is in accordance with the literature, ${ }^{29}$ and all NMR spectra are shown in Figures S1.8-11.

\section{(2,2-Dimethyl)-1,3-dioxolan-4-yl-4,5,5- $\left.d_{3}\right)$ methyl- $d_{2}(E)$-octadec-9-enoate- $d_{33}$}

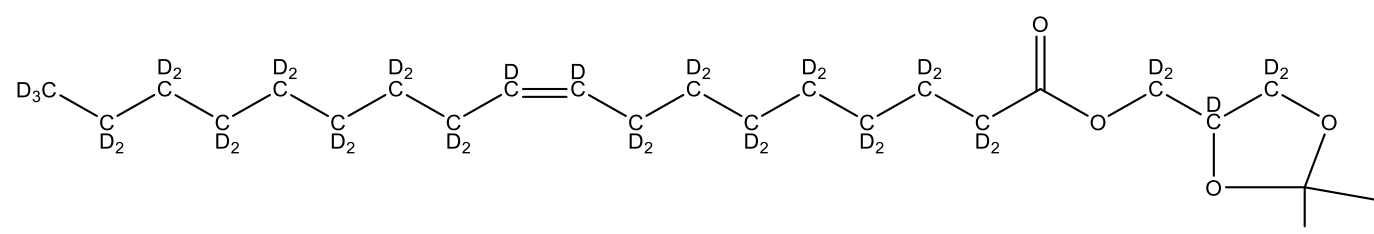

Figure S1.4. Chemical structure (2,2-Dimethyl)-1,3-dioxolan-4-yl-4,5,5- $\left.d_{3}\right)$ methyl- $d_{2}(E)$-octadec-9-enoate- $d_{33}$.

Oleic acid- $d_{33}(2.75 \mathrm{~g}, 8.74 \mathrm{mmol})$ and solketal- $\mathrm{d}_{5}(1.14 \mathrm{~g}, 8.31 \mathrm{mmol})$ were dissolved in dry DCM (200 mL) and DMAP (1.05 g, $8.59 \mathrm{mmol})$ was added. When all of the reagents had dissolved, the vessel was covered with foil and a $1.0 \mathrm{M}$ solution of DCC in DCM $(13.0 \mathrm{~mL}, 13.0 \mathrm{mmol})$ was added and the reaction mixture was allowed to stir at rt overnight. The mixture was filtered and the residue was washed with DCM (100 $\mathrm{mL}$ ); then the filtrate was concentrated to afford a yellow oil with suspended white solid. The suspension was dissolved in 5\% EtOAc in petroleum ether and re-filtered; the filtrate was again concentrated to provide a yellow oil with a reduced amount of suspended white solid. Flash column chromatography (5\% EtOAc in petroleum ether) provided the pure title compound as a clear oil $(2.37 \mathrm{~g}, 63 \%) .{ }^{1} \mathrm{H} \mathrm{NMR}\left(\mathrm{CDCl}_{3}\right.$, $400 \mathrm{MHz}$ ) $\delta 0.85$ (m, res.), 1.23 (m, res.), $1.36(\mathrm{~s}, 3 \mathrm{H}), 1.43(\mathrm{~s}, 3 \mathrm{H}), 1.62$ (s, residual), 1.95 (s, residual), 2.30 (s, residual), 3.71 (s, res.), 4.04-4.06 (complex, res.), 4.13 (s, res.), 4.29 (s, res.), 5.32 (s, $1 \mathrm{H}) .{ }^{2} \mathrm{H} \mathrm{NMR}\left(\mathrm{CDCl}_{3}\right.$, $61.4 \mathrm{MHz}) \delta 0.82(\mathrm{~s}), 1.22(\mathrm{~s}), 1.57(\mathrm{~s}), 1.96(\mathrm{~s}), 2.31(\mathrm{~s}), 3.73(\mathrm{~s}), 4.06(\mathrm{~s}), 4.15(\mathrm{~s}), 4.30(\mathrm{~s}), 5.39(\mathrm{~s}) .{ }^{13} \mathrm{C}$ NMR [ ${ }^{1} \mathrm{H}$-decoupled] $\left(\mathrm{CDCl}_{3}, 100 \mathrm{MHz}\right) \delta 13.1(\mathrm{~m}), 21.5(\mathrm{~m}), 23.9(\mathrm{~m}), 25.3(\mathrm{~m}), 25.5(\mathrm{~s}), 26.5(\mathrm{~m}), 26.8(\mathrm{~s}), 28.1$ $(\mathrm{m}), 30.6(\mathrm{~m}), 33.5(\mathrm{~m}), 64.0(\mathrm{~m}), 65.7(\mathrm{~m}), 73.2(\mathrm{~m}), 109.9(\mathrm{~s}), 129.7(\mathrm{~s}), 173.8(\mathrm{~s}) .{ }^{13} \mathrm{C} \mathrm{NMR}\left[{ }^{1} \mathrm{H}\right.$ and ${ }^{2} \mathrm{H}$ decoupled] $\left(\mathrm{CDCl}_{3}, 100 \mathrm{MHz}\right) \delta$ 13.1, 21.5, 23.9, 25.5, 26.29, 26.31, 26.8, 27.89, 27.91, 27.96, 28.1, 28.3, 28.59, 28.65, 30.6, 33.4, 63.9, 65.7, 73.2, 109.9, 129.65, 129.73, 173.8. MS (ESI+) $\mathrm{m} / \mathrm{z}$ calculated for $\mathrm{C}_{24} \mathrm{H}_{7} \mathrm{D}_{37} \mathrm{NaO}_{4}[\mathrm{M}+\mathrm{Na}]^{+}$as 456.5 ; found: 456.6 (100\%). NMR spectra for this compound are shown in Figures S1.12-15. 


\section{Glycero-1-monoolein-d ${ }_{38}\left(1-O l e o y l-r a c-\right.$ glycerol-d $\left._{38}\right)$}

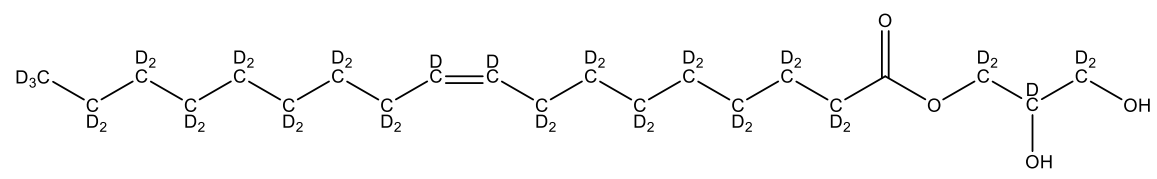

Figure S1.5. Chemical structure glycero-1-monoolein- $d_{38}$ (1-Oleoyl-rac-glycerol- $\left.d_{38}\right)$.

Acetonide-protected GMO- $\mathrm{d}_{38}(2.33 \mathrm{~g}, 5.36 \mathrm{mmol})$ was added to a mixture of ethanol and water $(95: 5 ; 60$ $\mathrm{mL}$ ). Amberlyst resin ( $5.8 \mathrm{~g}$ ) which had been successively washed with methanol ( $3 \times 20 \mathrm{~mL}$ ) then ethanol $\left(20 \mathrm{~mL}\right.$ ) was added and the mixture was heated to $90^{\circ} \mathrm{C}$ for $2 \mathrm{~h}$. The mixture was cooled, filtered and the residue washed with $\mathrm{EtOH}(50 \mathrm{~mL})$. The filtrate was concentrated to afford a pale brown oil. Flash column chromatography (100\% DCM to 20\% EtOAc in DCM) provided the title compound as a clear oil (1.62 g, 77\%). 2D NMR suggested the presence of a small amount of 2-oleoyl-rac-glycerol-d $\mathrm{d}_{38} .{ }^{1} \mathrm{H} \mathrm{NMR}\left(\mathrm{CDCl}_{3}, 400\right.$ $\mathrm{MHz}$ ) $\delta 0.81$ (s, res.), 1.20-1.29 (complex, res.), 1.57-1.61 (complex, res.), 1.95-2.32 (complex, res.), 3.57 (s, res.), 3.66 (s, res.), 3.79 (s, res., from 2-glycero-monoolein), 3.90 (s, res.), 4.12 (s, res.), 4.17 (s, res.), $5.32(\mathrm{~s}) .{ }^{2} \mathrm{H} \mathrm{NMR}\left(\mathrm{CDCl}_{3}, 61.4 \mathrm{MHz}\right) \delta 0.82(\mathrm{~s}), 1.22(\mathrm{~s}), 1.58(\mathrm{~s}), 1.96(\mathrm{~s}), 2.31(\mathrm{~s}), 3.58(\mathrm{~s}), 3.67(\mathrm{~s}), 3.81(\mathrm{~s}$, from 2-glycero-monoolein), 3.91 (s), $4.14(\mathrm{~s}), 4.18(\mathrm{~s}), 5.38(\mathrm{~s}) .{ }^{13} \mathrm{C} \mathrm{NMR}\left[{ }^{1} \mathrm{H}\right.$-decoupled] $\left(\mathrm{CDCl}_{3}, 100 \mathrm{MHz}\right)$ $\delta 13.1(\mathrm{~m}), 21.5(\mathrm{~m}), 24.0(\mathrm{~m}), 26.3(\mathrm{~m}), 28.1(\mathrm{~m}), 30.6(\mathrm{~m}), 33.5(\mathrm{~m}), 62.7(\mathrm{~m}), 64.6(\mathrm{~m}), 69.7(\mathrm{t}), 129.6(\mathrm{~s})$, 174.6 (s). ${ }^{13} \mathrm{C}$ NMR $\left[{ }^{1} \mathrm{H}\right.$ and ${ }^{2} \mathrm{H}$-decoupled] $\left(\mathrm{CDCl}_{3}, 100 \mathrm{MHz}\right) \delta 13.1,21.5,23.9,26.3,26.7,27.88,27.91$, 28.0, 28.1, 28.3, 28.59, 28.65, 30.6, 33.5, 33.8, 62.7, 64.6, 69.7, 129.6, 129.8, 174.6. MS (ESI+) $\mathrm{m} / \mathrm{z}$ calculated for $\mathrm{C}_{21} \mathrm{H}_{3} \mathrm{D}_{37} \mathrm{NaO}_{4}[\mathrm{M}+\mathrm{Na}]^{+}$as 416.5 ; found: 416.5 (100\%). All NMR spectra are shown in Figures S1.16-19.

\section{Glycero-1-monoolein-d 40 (1-Oleoyl-rac-glycerol-d $\left.\mathrm{d}_{40}\right)$ D-MO}

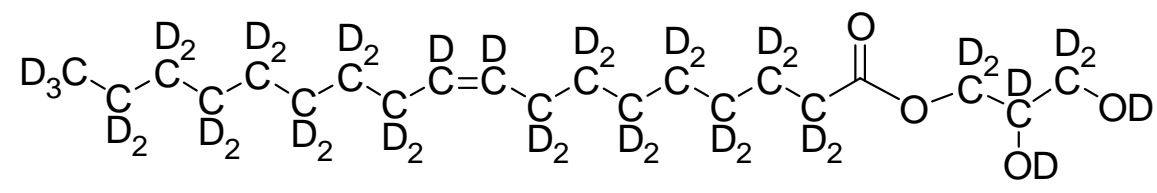

Figure S1.6. Chemical structure glycero-1-monoolein- $\mathrm{d}_{40}$ (1-Oleoyl-rac-glycerol-d $\left.\mathrm{d}_{40}\right)$ D-MO.

GMO-d $\mathrm{d}_{38}(1 \mathrm{~g})$ was dissolved in MeOD $(5 \mathrm{~mL}$ ) and stirred for 30 minutes at room temperature, with the MeOD removed under reduced pressure and this process repeated once more. This exchange process was first performed on H-MO with the FTIR spectrum shown in Figure S1.7. No FTIR data was obtained for D$\mathrm{MO}$ due to the contamination/sacrifice of material that would be required to collect a spectrum. 


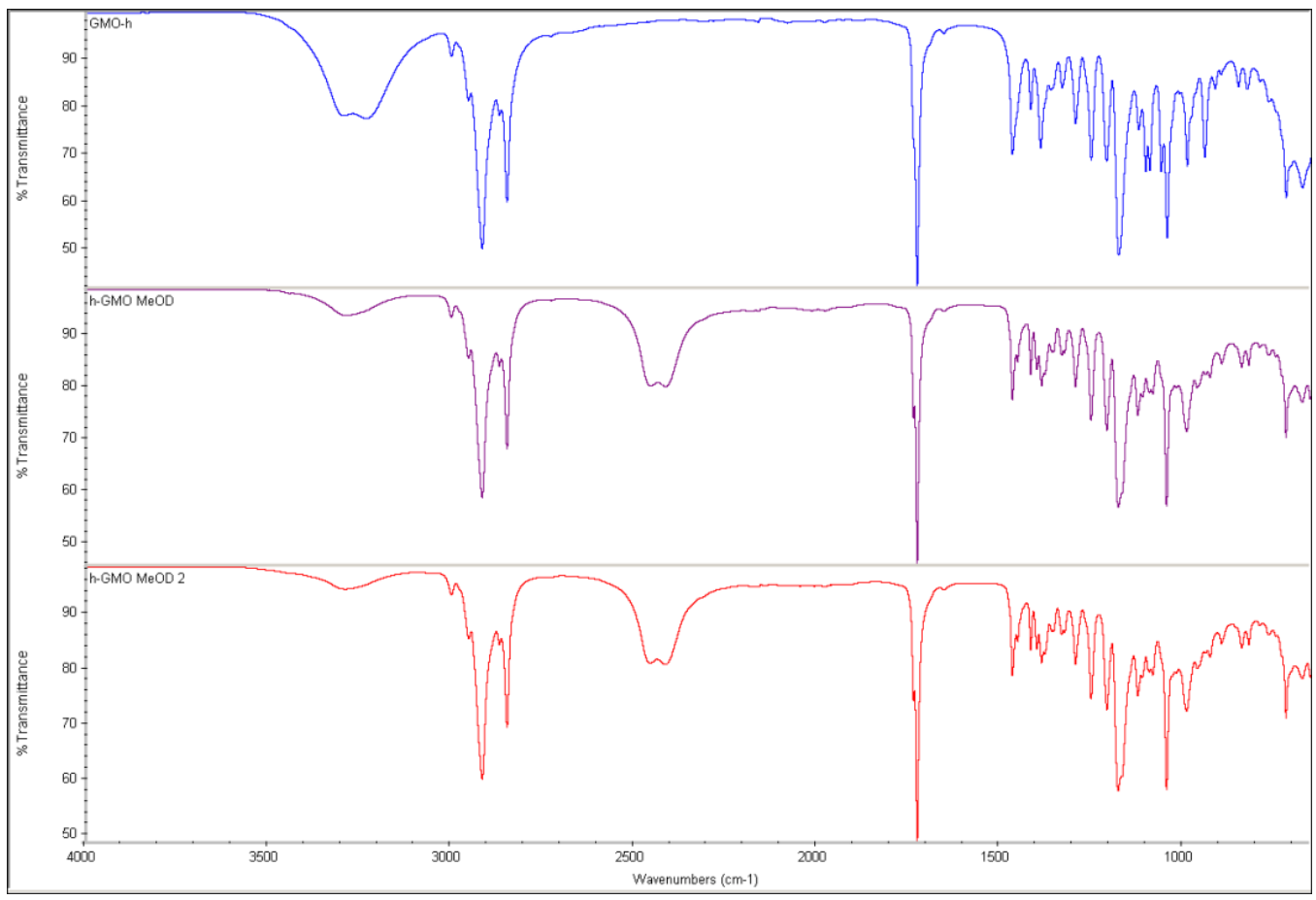

Figure S1.7. FTIR spectrum of H-MO (top), H-MO after one exchange cycle with MeOD (middle), and after a second exchange cycle (bottom). The exchange of the majority of the alcoholic protons is confirmed by the reduction in the intensity of the $\mathrm{O}-\mathrm{H}$ stretch at $\sim 3250 \mathrm{~cm}^{-1}$ and the appearance of the O-D stretch at $\sim 2450 \mathrm{~cm}^{-1}$. 


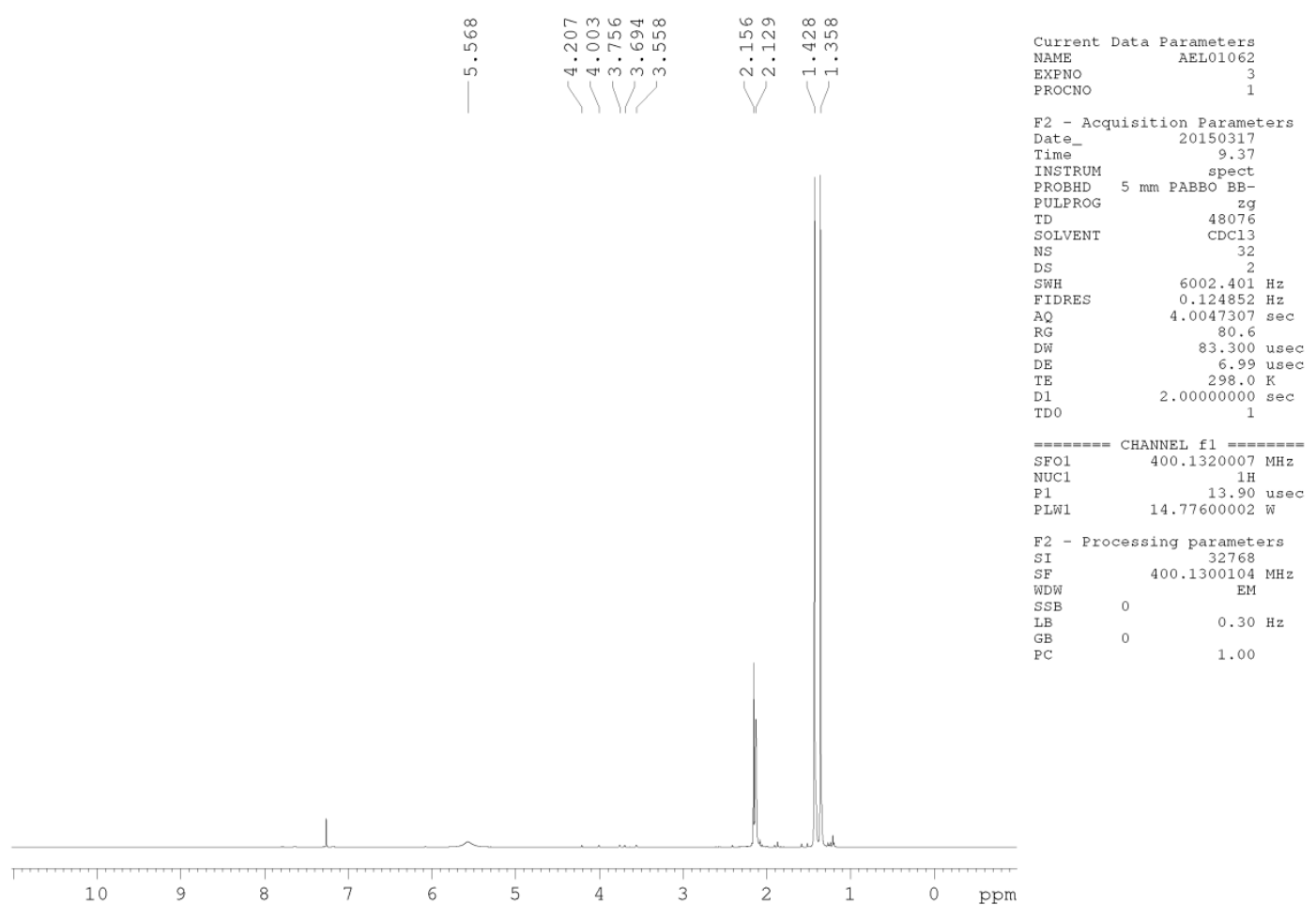

Figure S1.8. ${ }^{1} \mathrm{H}$ NMR spectrum of (2,2-dimethyl-[1,3]-dioxolan-4-yl)-methanol-d $d_{5}$ (solketal- $\left.d_{5}\right)\left(400 \mathrm{MHz}, \mathrm{CDCl}_{3}\right)$.

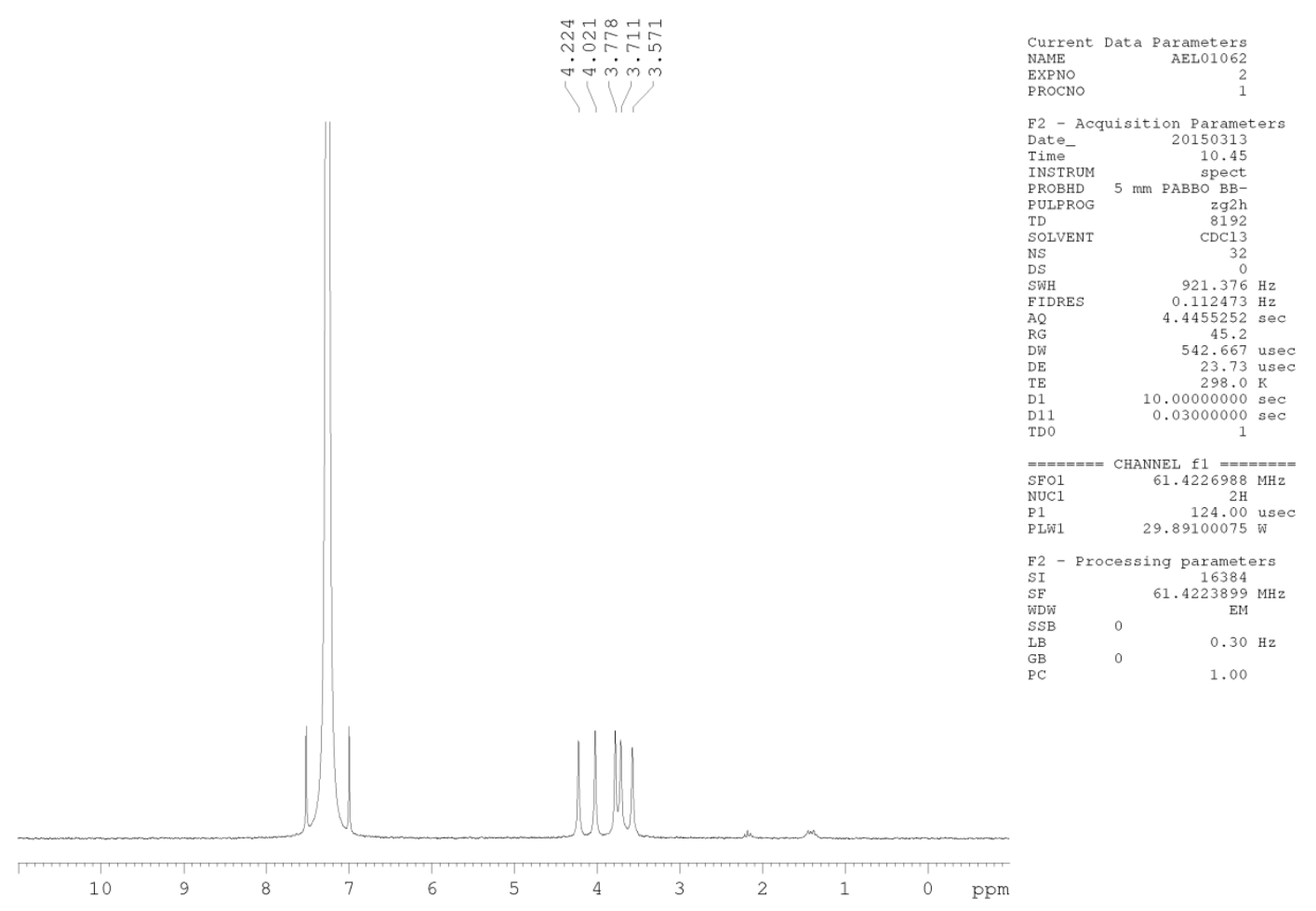

Figure S1.9. ${ }^{2} \mathrm{H}$ NMR spectrum of (2,2-dimethyl-[1,3]-dioxolan-4-yl)-methanol- $d_{5}$ (solketal- $\left.d_{5}\right)\left(61.4 \mathrm{MHz}, \mathrm{CDCl}_{3}\right)$. 


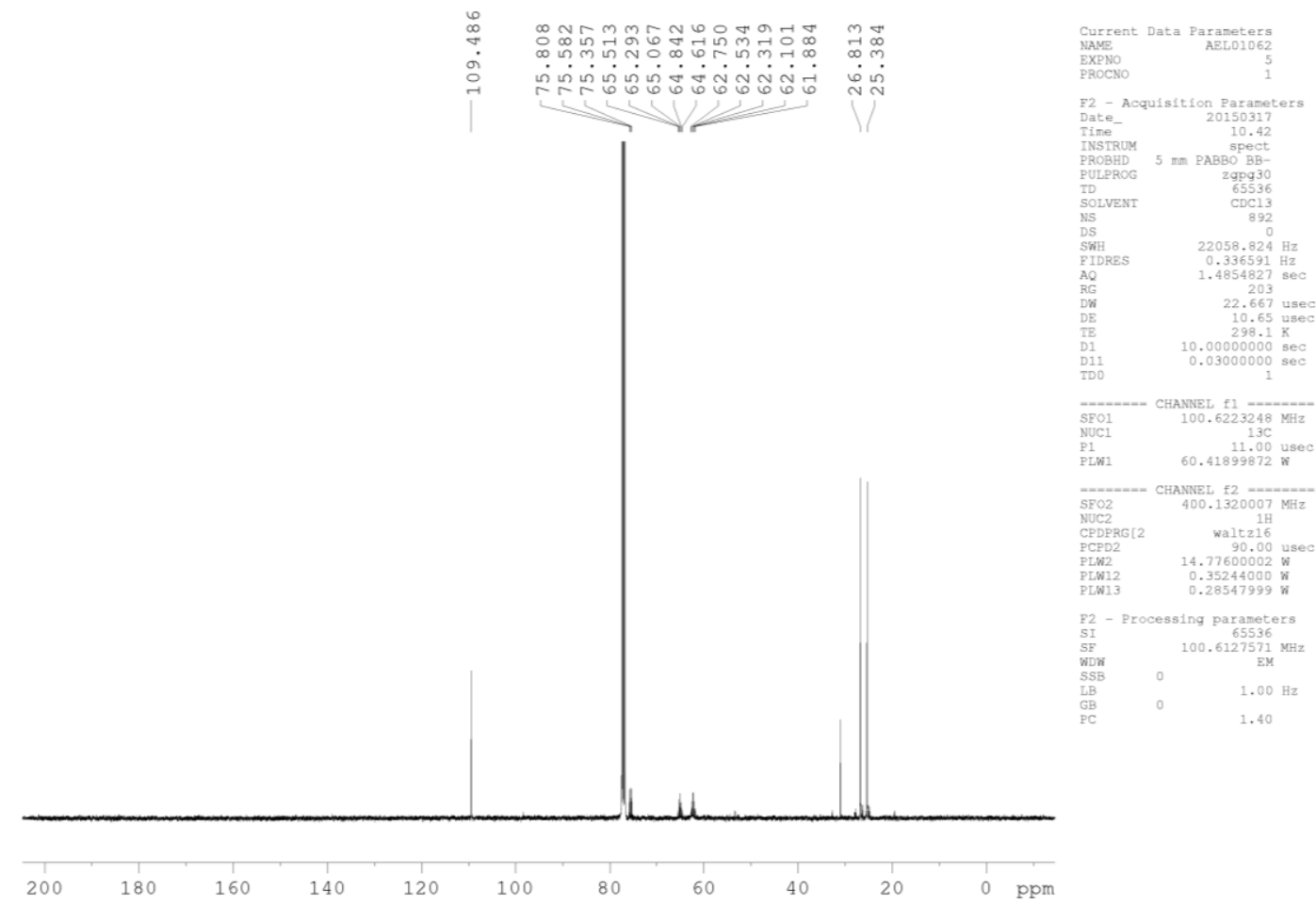

Figure S1.10. ${ }^{13} \mathrm{C}$ NMR spectrum of (2,2-dimethyl-[1,3]-dioxolan-4-yl)-methanol- $d_{5}$ (solketal- $\left.d_{5}\right)\left(100 \mathrm{MHz}, \mathrm{CDCl}_{3}\right)$.

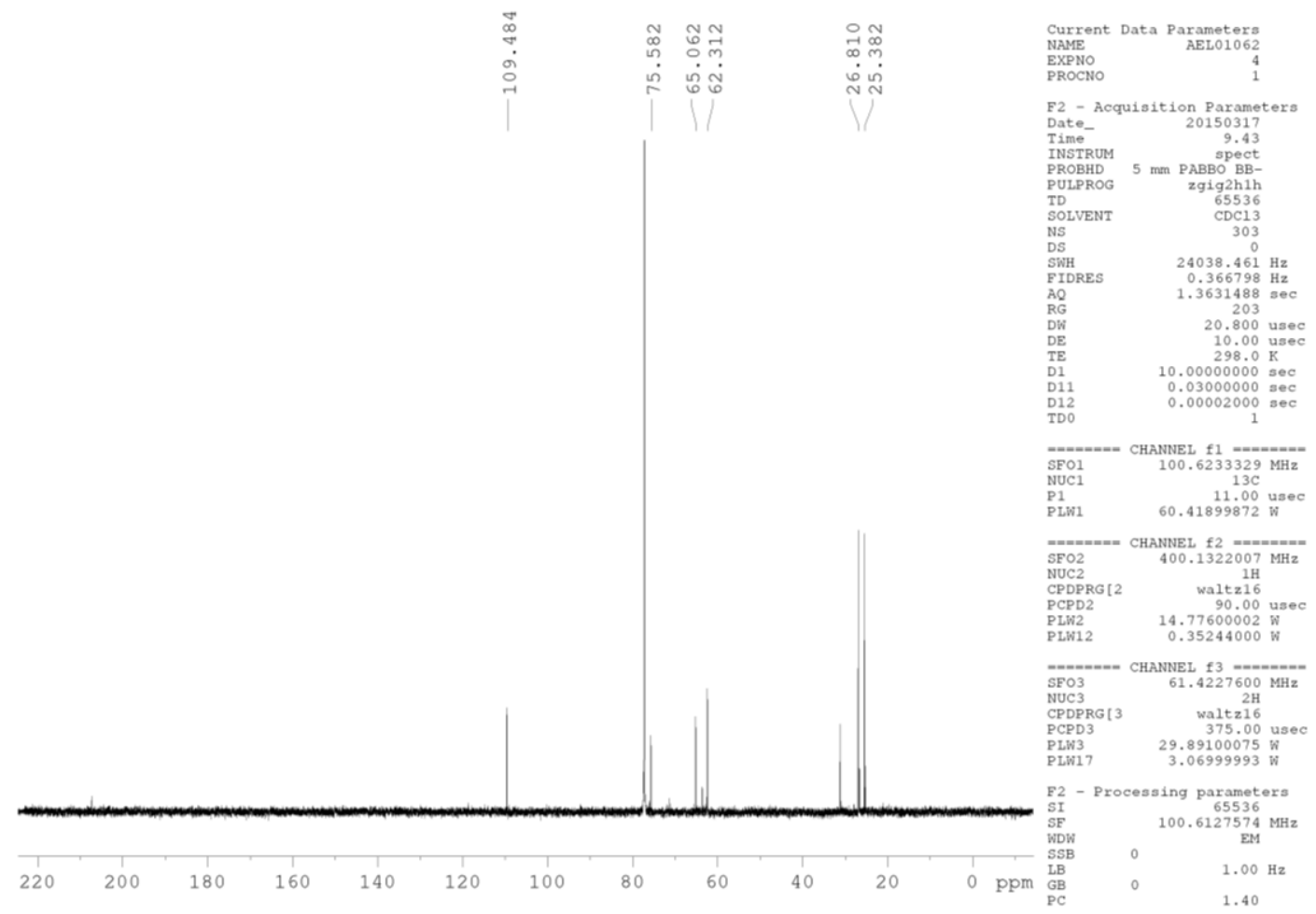

Figure S1.11. ${ }^{13} \mathrm{C}$ NMR $\left[{ }^{1} \mathrm{H}\right.$ and ${ }^{2} \mathrm{H}$ decoupled] spectrum of (2,2-dimethyl-[1,3]-dioxolan-4-yl)-methanol- $d_{5}$ (solketal- $\left.d_{5}\right)(100 \mathrm{MHz}$, $\left.\mathrm{CDCl}_{3}\right)$. 


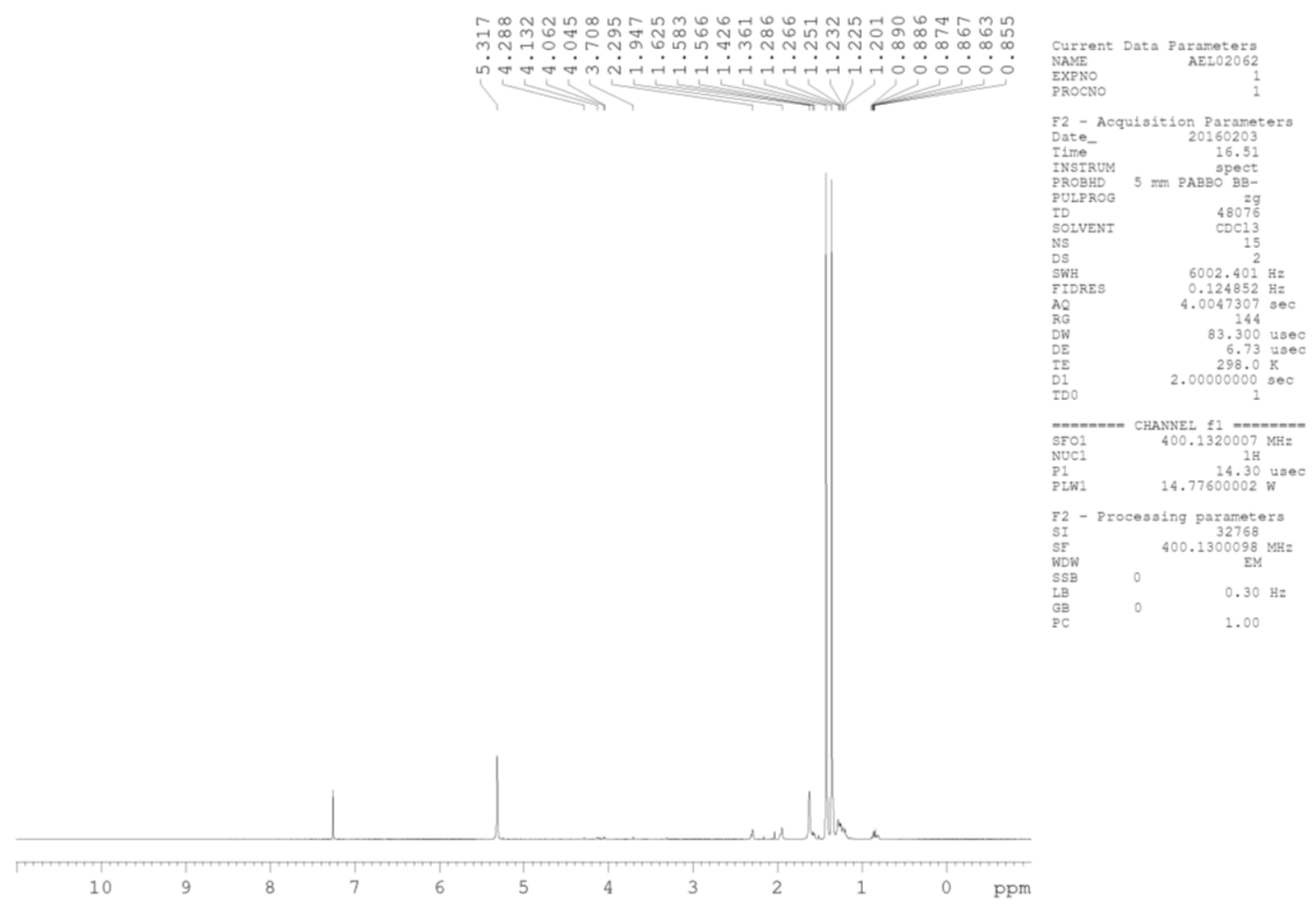

Figure S1.12. ${ }^{1 \mathrm{H}}$ NMR spectrum of (2,2-dimethyl)-1,3-dioxolan-4-yl-4,5,5- $\left.\mathrm{d}_{3}\right)$ methyl- $\mathrm{d}_{2}(E)$-octadec-9-enoate- $d_{33}\left(400 \mathrm{MHz}, \mathrm{CDCl}{ }_{3}\right)$.

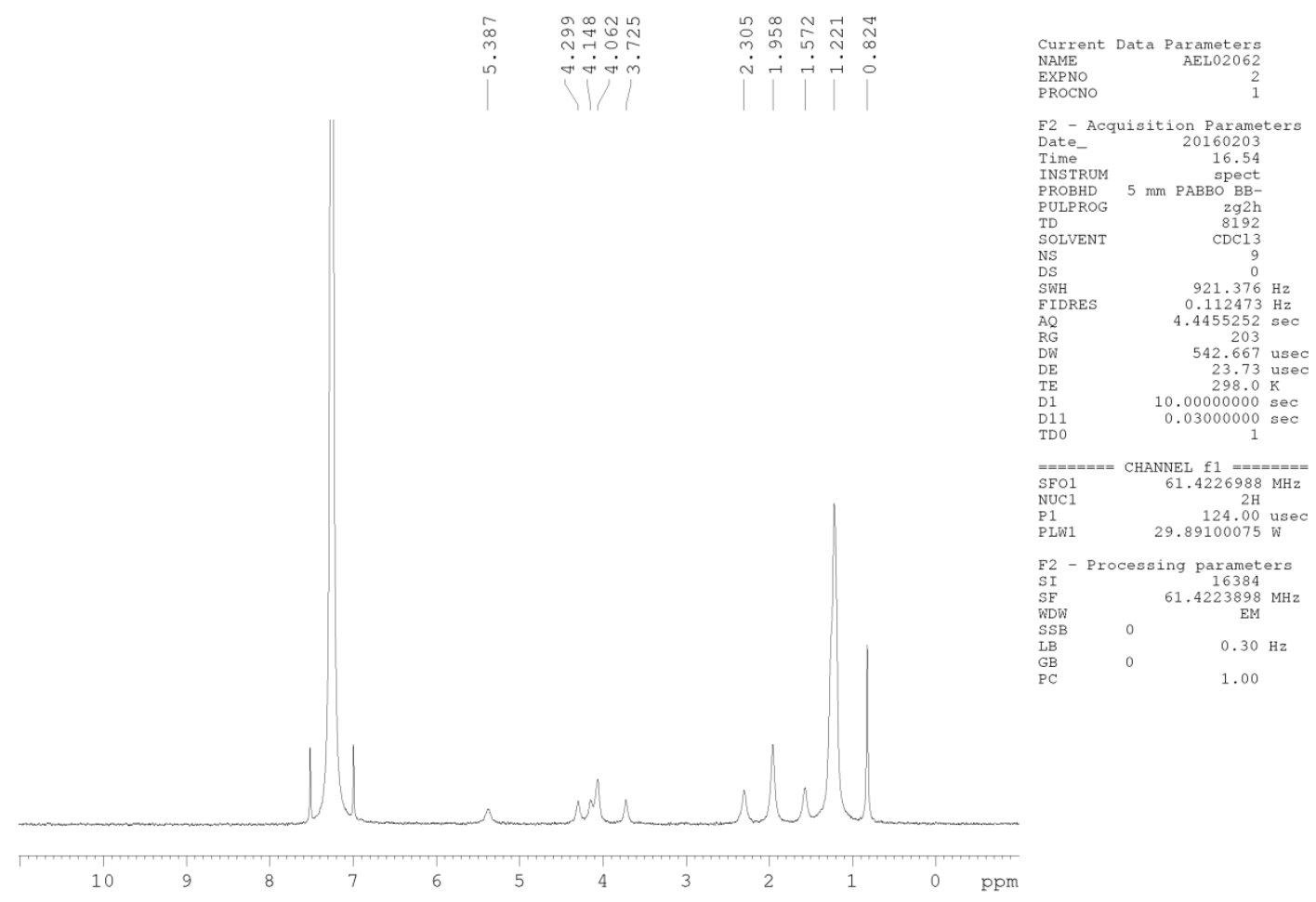

Figure S1.13. ${ }^{2} \mathrm{H}$ NMR spectrum of (2,2-dimethyl)-1,3-dioxolan-4-yl-4,5,5- $\left.\mathrm{d}_{3}\right)$ methyl- $\mathrm{d}_{2}$ (E)-octadec-9-enoate- $d_{33}$ (61.4 MHz, $\left(\mathrm{CDCl}_{3}\right)$. 


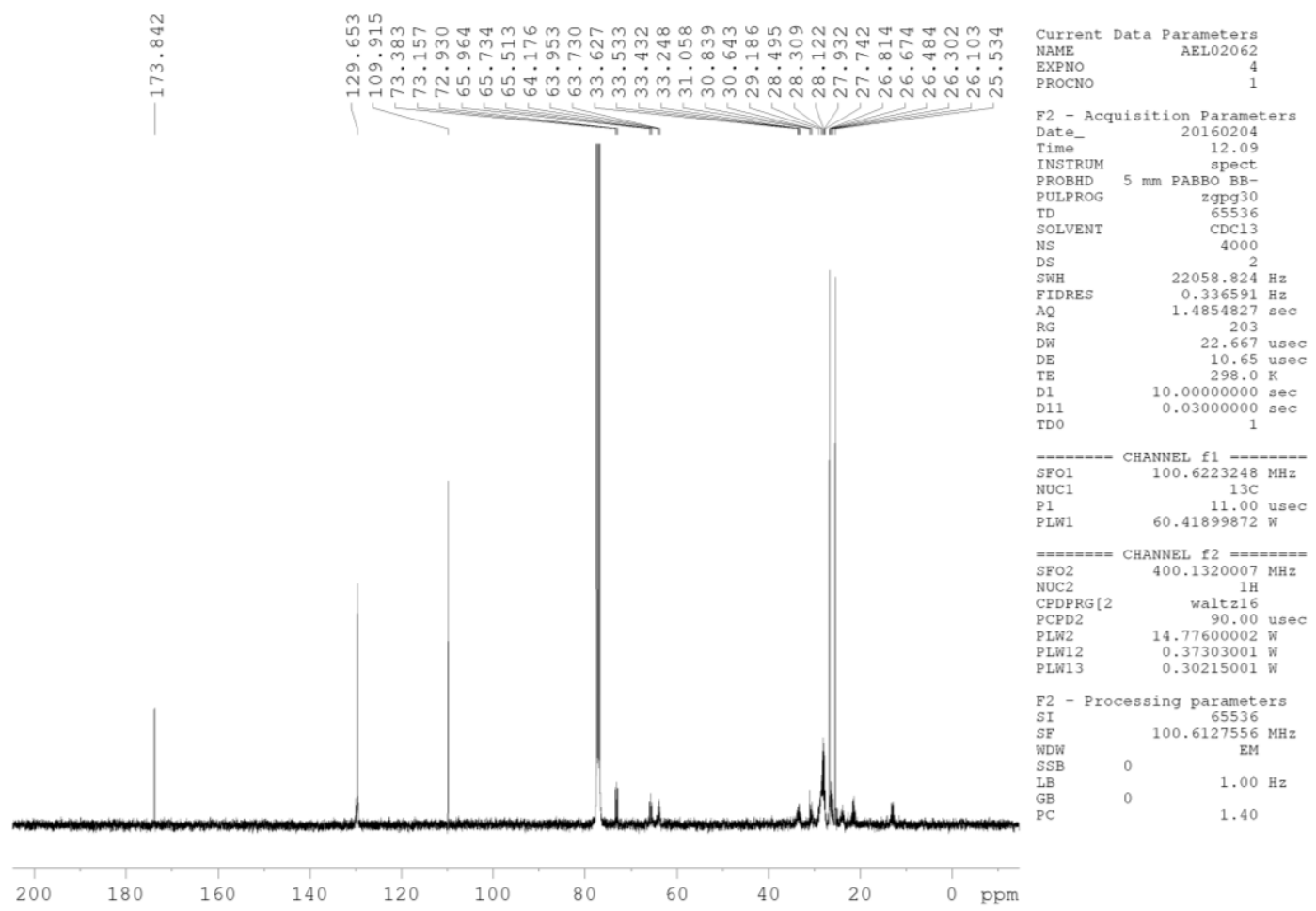

Figure S1.14. ${ }^{13} \mathrm{C}$ NMR spectrum of (2,2-dimethyl)-1,3-dioxolan-4-yl-4,5,5- $\left.d_{3}\right)$ methyl- $d_{2}(E)$-octadec-9-enoate- $d_{33}$ (100 MHz, $\left.\mathrm{CDCl}_{3}\right)$.

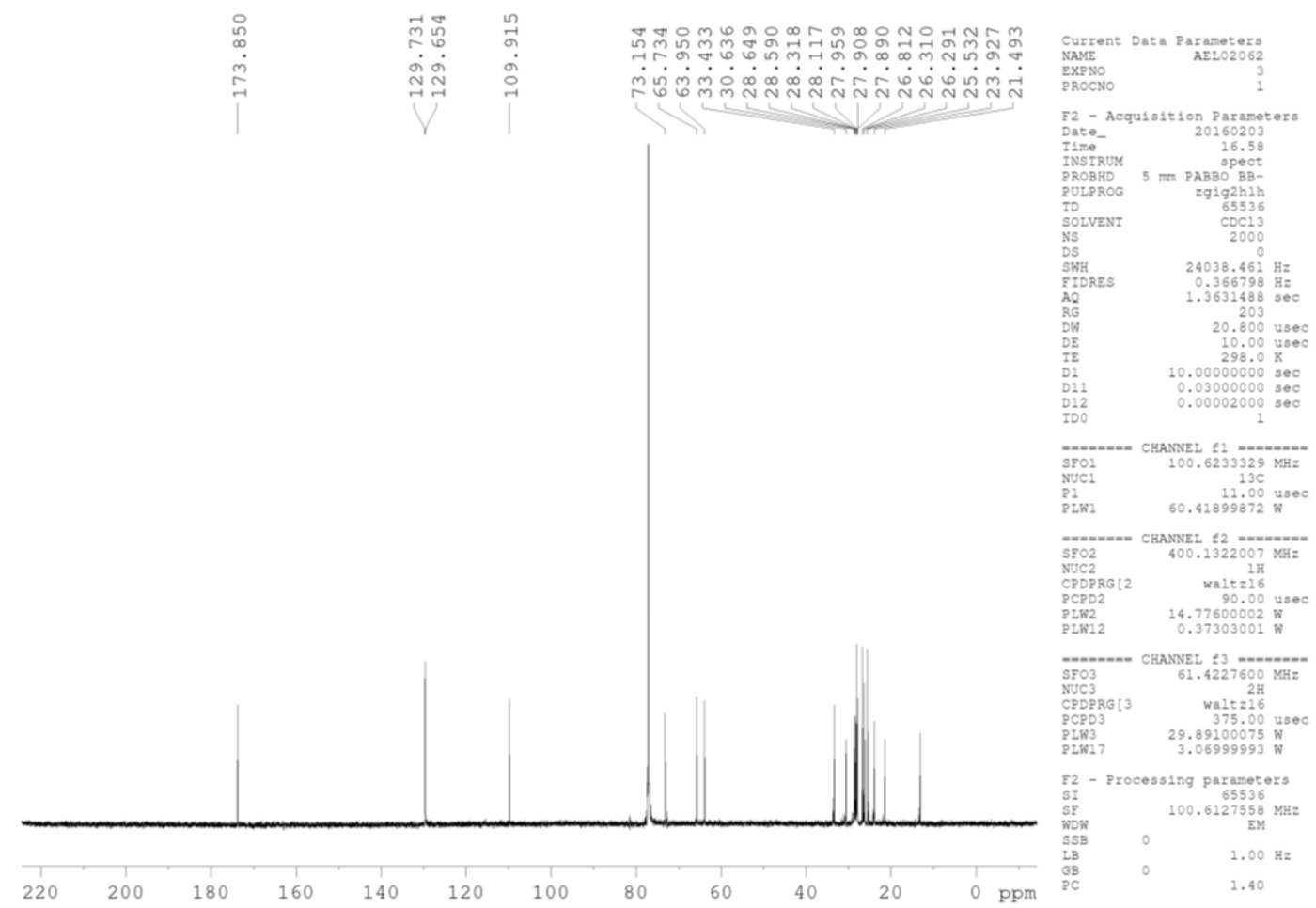

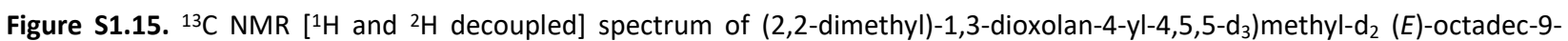
enoate- $d_{33}\left(100 \mathrm{MHz}, \mathrm{CDCl}_{3}\right)$. 


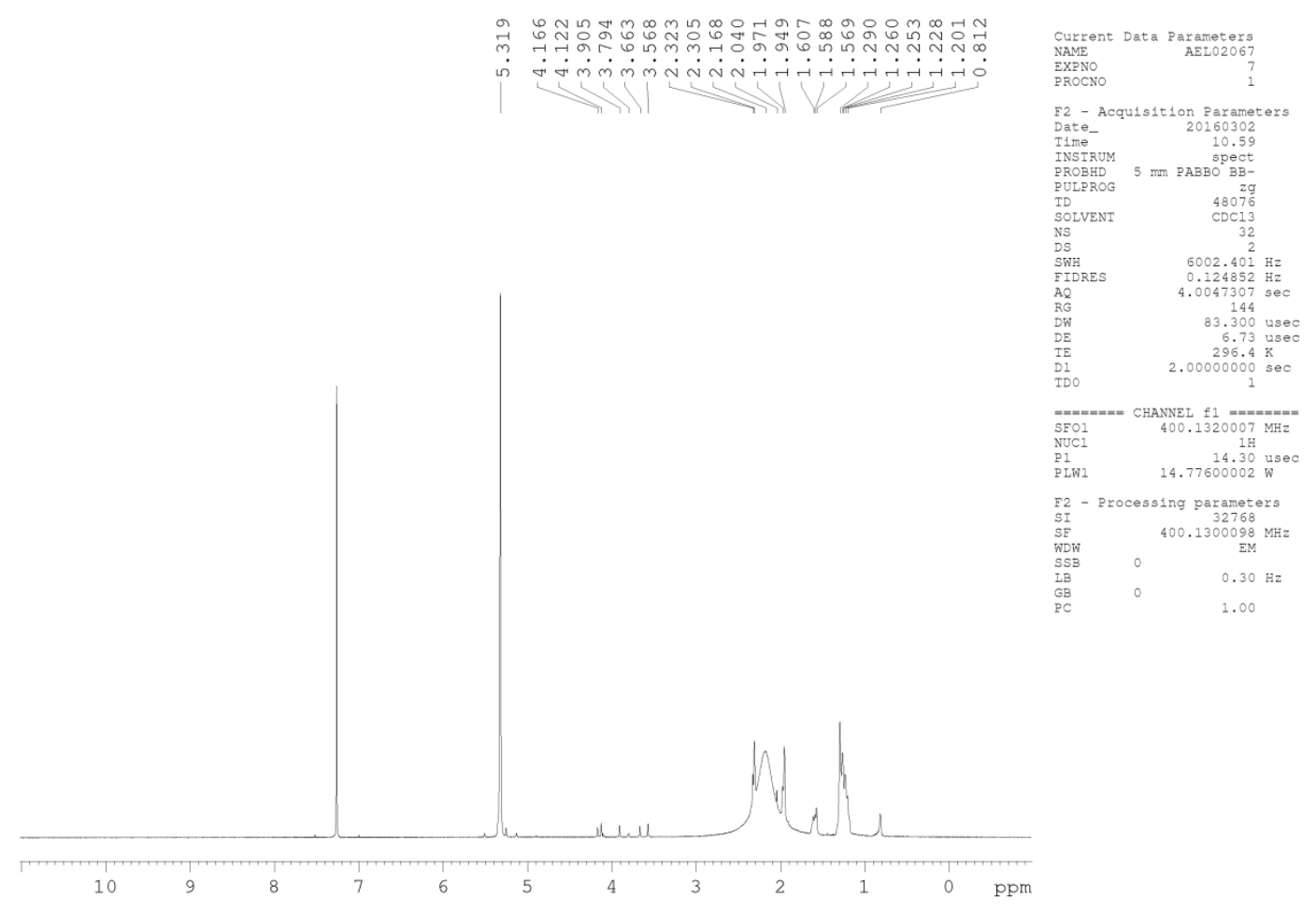

Figure S1.16. ${ }^{1 \mathrm{H}}$ NMR of glycero-1-monoolein- $\mathrm{d}_{38}$ (1-oleoyl-rac-glycerol- $\left.\mathrm{d}_{38}\right)\left(400 \mathrm{MHz}, \mathrm{CDCl}_{3}\right)$.

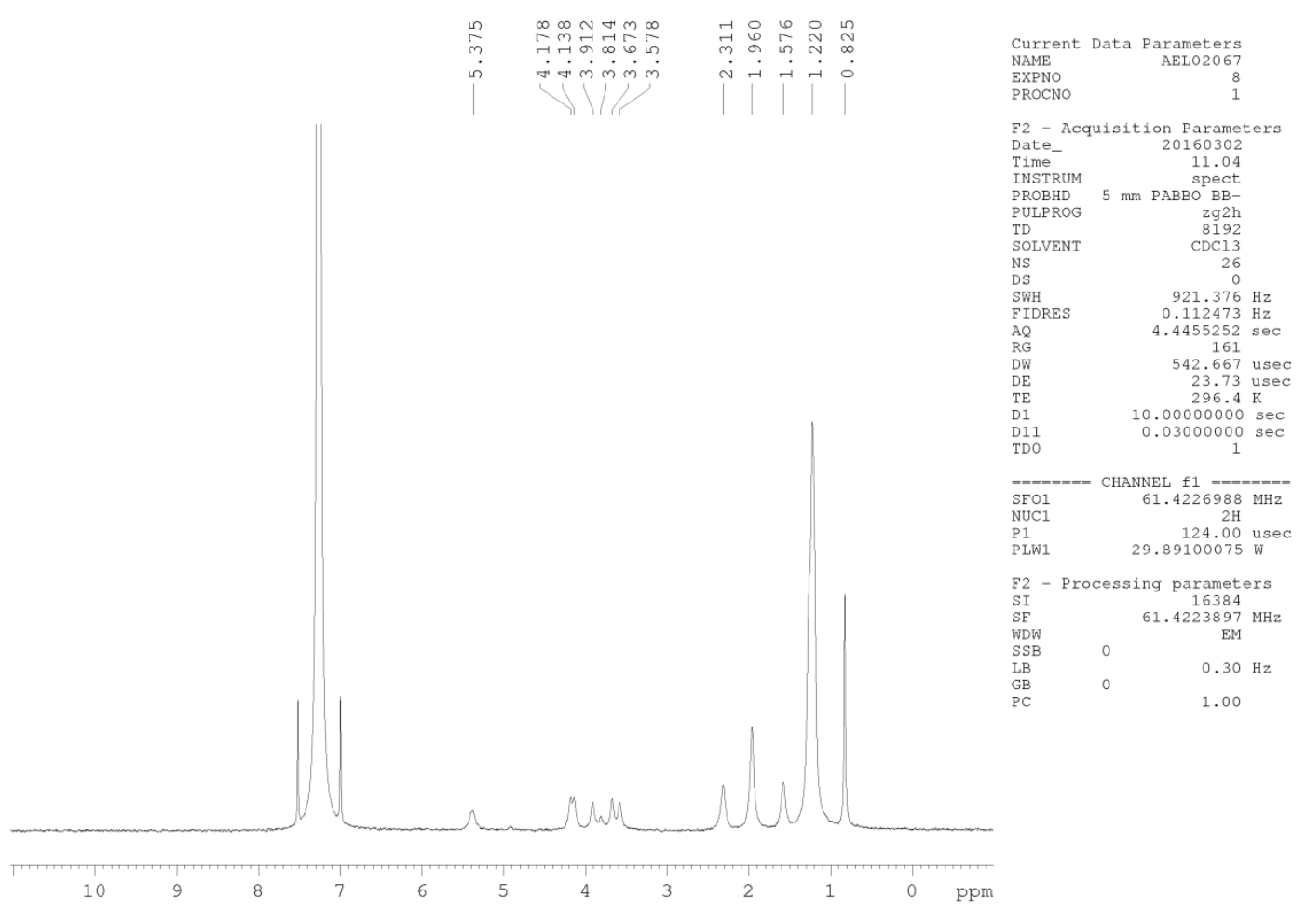

Figure S1.17. ${ }^{2} \mathrm{H}$ NMR of glycero-1-monoolein- $\mathrm{d}_{38}$ (1-oleoyl-rac-glycerol- $\left.\mathrm{d}_{38}\right)\left(61.4 \mathrm{MHz}, \mathrm{CDCl}_{3}\right)$. 


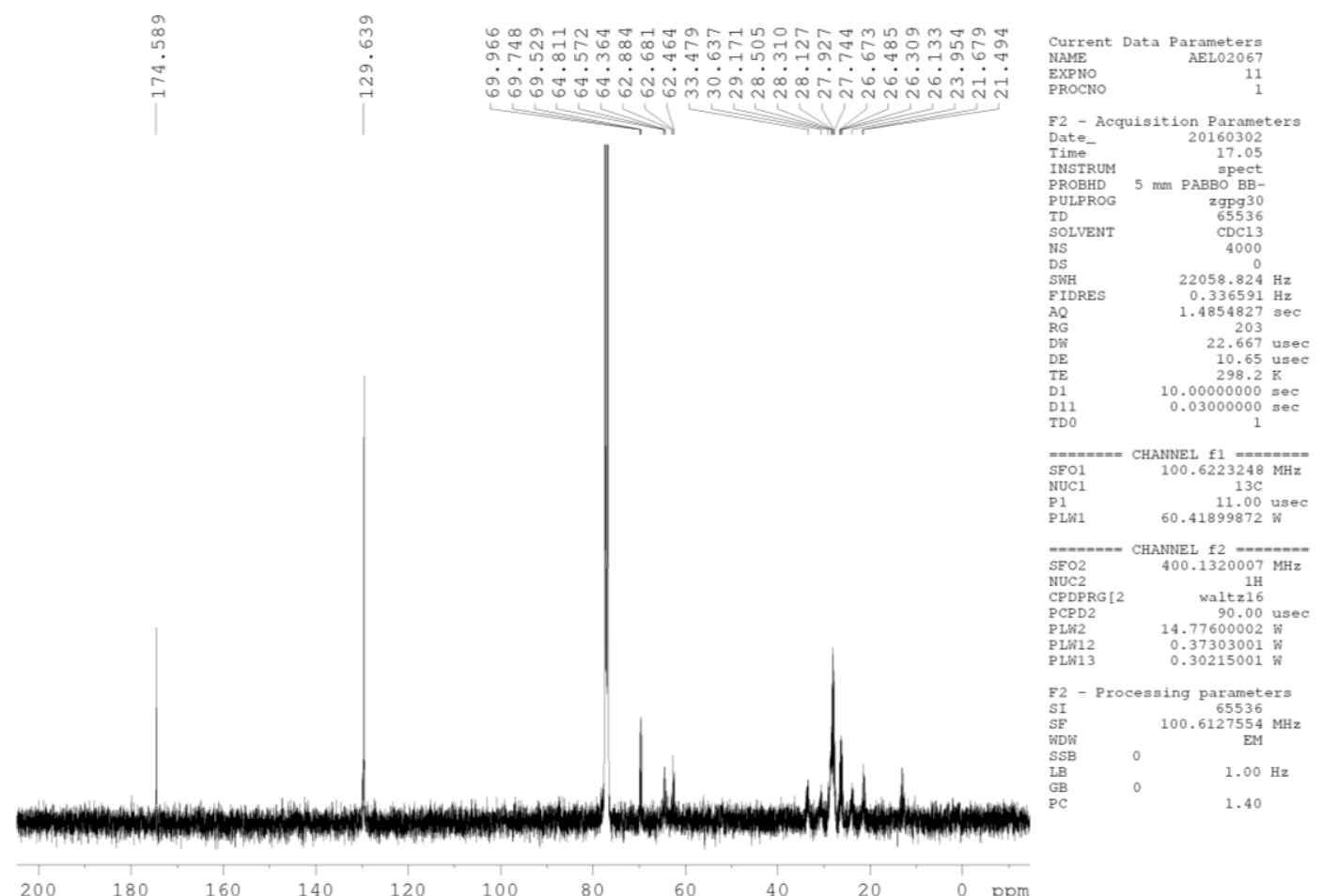

Figure S1.18. ${ }^{13} \mathrm{C}$ NMR of glycero-1-monoolein- $\mathrm{d}_{38}$ (1-oleoyl-rac-glycerol- $\left.\mathrm{d}_{38}\right)\left(100 \mathrm{MHz}, \mathrm{CDCl}_{3}\right)$.

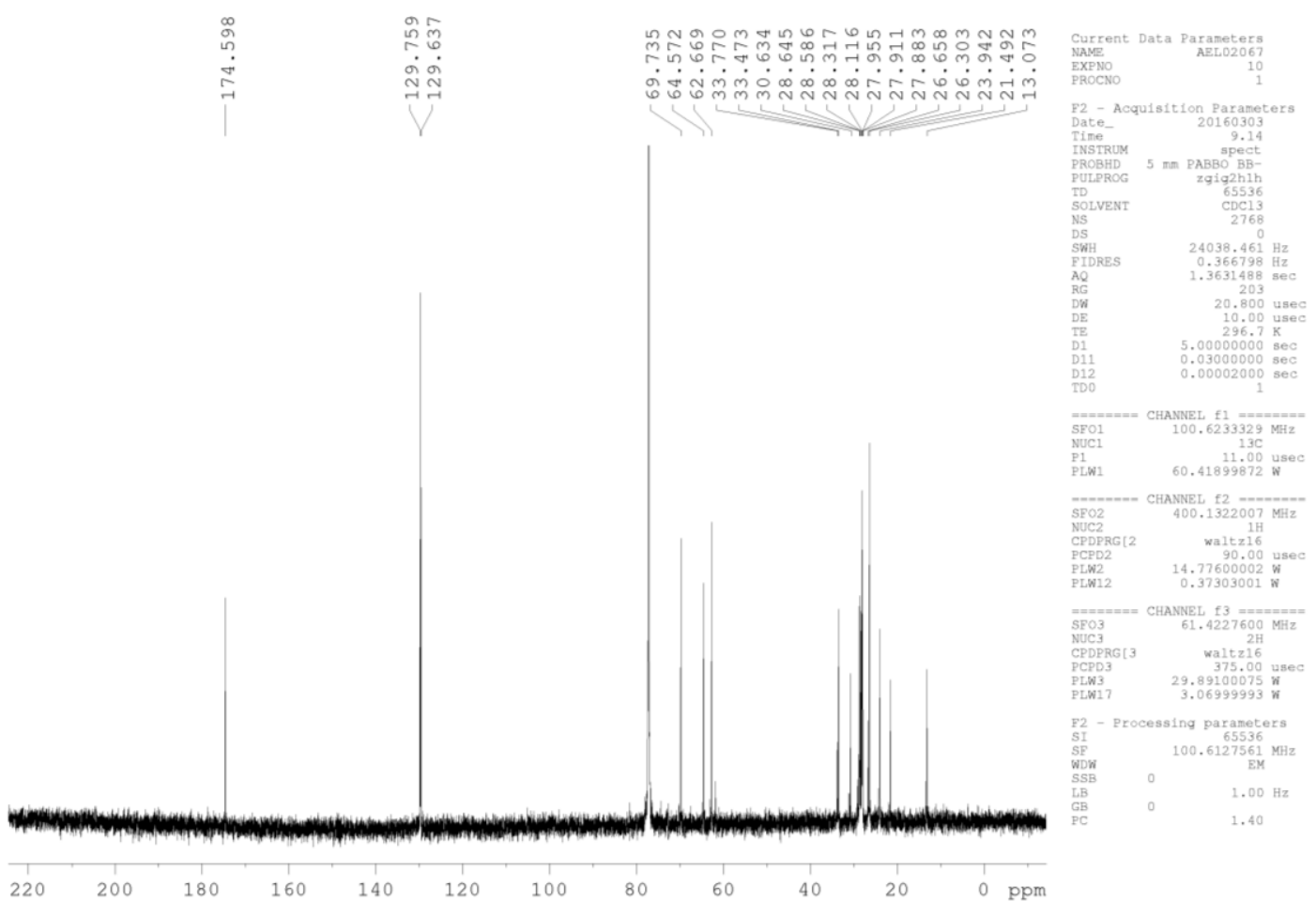

Figure S1.19. ${ }^{13} \mathrm{C}$ NMR $\left[{ }^{1} \mathrm{H}\right.$ and ${ }^{2} \mathrm{H}$ decoupled] of glycero-1-monoolein- $\mathrm{d}_{38}$ (1-oleoyl-rac-glycerol- $\left.\mathrm{d}_{38}\right)\left(100 \mathrm{MHz}, \mathrm{CDCl}_{3}\right)$. 


\section{Supporting Information 2: Scattering Length Densities Crystallization Screen conditions}

Table S2.1. Scattering length densities of buffer and salt conditions used for DAP12 and GpA crystallization.

\begin{tabular}{|c|c|c|c|c|c|}
\hline & $\begin{array}{l}\text { Chemical } \\
\text { Formula }\end{array}$ & $\begin{array}{c}\text { Density salt } \\
\qquad\left(\mathrm{g} \mathrm{cm}^{-3}\right)\end{array}$ & $\begin{array}{c}\text { Molecular } \\
\text { weight }\left(\mathrm{g} \mathrm{mol}^{-1}\right)\end{array}$ & $\begin{array}{c}\text { SLD salt } \\
\left(\times 10-6 \AA^{-2}\right) \\
\end{array}$ & $\begin{array}{l}\text { SLD in } D_{2} O \\
\left(x 10-6 \AA^{-2}\right) \\
\end{array}$ \\
\hline $\mathrm{D}_{2} \mathrm{O}$ & $\mathrm{D}_{2} \mathrm{O}$ & 1.11 & 20.03 & 6.37 & 6.37 \\
\hline $\begin{array}{l}\text { Bis-Tris propane (D- } \\
\text { exchanged) } 0.1 \mathrm{M}\end{array}$ & $\mathrm{C}_{11} \mathrm{H}_{18} \mathrm{D}_{8} \mathrm{~N}_{2} \mathrm{O}_{6}$ & 1.30 & 290.3 & 3.04 & 6.30 \\
\hline $\mathrm{HCl} 0.14 \mathrm{M}$ & $\mathrm{HCl}$ & 1.02 & 36.46 & 0.981 & 6.28 \\
\hline $\mathrm{CaCl}_{2} 0.05 \mathrm{M}$ & $\mathrm{CaCl}_{2}$ & 2.15 & 111.0 & 2.78 & 6.36 \\
\hline $\begin{array}{l}\mathrm{H}_{2} \mathrm{O} 0.1 \mathrm{M} \text { (from } \\
\mathrm{CaCl}_{2} * 2 \mathrm{H}_{2} \mathrm{O} \text { ) }\end{array}$ & $\mathrm{H}_{2} \mathrm{O}$ & 0.998 & 18.02 & -0.56 & 6.35 \\
\hline Screen / Buffer A & & & & $\begin{array}{l}0.1 \mathrm{M} \text { Bis-tris ( } p H \\
6.4), 0.05 \mathrm{M} \mathrm{CaCl}_{2}\end{array}$ & 6.21 \\
\hline $\begin{array}{l}\text { Tris chloride (D- } \\
\text { exchanged) } 0.1 \mathrm{M}\end{array}$ & $\mathrm{C}_{4} \mathrm{H}_{8} \mathrm{D}_{3} \mathrm{NO}_{3}$ & 1.40 & 124.1 & 2.77 & 6.34 \\
\hline $\mathrm{HCl} 0.069 \mathrm{M}$ & $\mathrm{HCl}$ & 1.02 & 36.46 & 0.981 & 6.33 \\
\hline $\mathrm{MgCl}_{2} 0.2 \mathrm{M}$ & $\mathrm{MgCl}_{2}$ & 2.32 & 95.21 & 3.60 & 6.35 \\
\hline $\begin{array}{l}\mathrm{H}_{2} \mathrm{O} 1.2 \mathrm{M} \text { (from } \\
\mathrm{MgCl}_{2} * 6 \mathrm{H}_{2} \mathrm{O} \text { ) }\end{array}$ & $\mathrm{H}_{2} \mathrm{O}$ & 1 & 18.00 & -0.56 & 6.20 \\
\hline Screen B & & & & $\begin{array}{c}0.1 \mathrm{M} \text { Tris (pH 8), } \\
0.2 \mathrm{M} \mathrm{MgCl}_{2}\end{array}$ & 6.14 \\
\hline $\begin{array}{l}\text { Tris chloride chloride } \\
\text { (D-exchanged) } 12.5 \\
\mathrm{mM}\end{array}$ & $\mathrm{C}_{4} \mathrm{H}_{8} \mathrm{D}_{3} \mathrm{NO}_{3}$ & 1.4 & 124.1 & 2.77 & 6.37 \\
\hline HCl 15 mM final & $\mathrm{HCl}$ & 1.02 & 36.46 & 0.981 & 6.37 \\
\hline $\mathrm{NaCl} 40 \mathrm{mM}$ & $\mathrm{NaCl}$ & 2.16 & 58.44 & 2.94 & 6.37 \\
\hline Buffer $B$ & & & & $\begin{array}{l}12.5 \mathrm{mM} \text { Tris ( } p H \\
8), 40 \mathrm{mM} \mathrm{NaCl}\end{array}$ & 6.36 \\
\hline
\end{tabular}




\section{Supporting Information 3: Peak intensity as a function of temperature (hydration).}

SANS measurements for $\mathrm{H}-\mathrm{MO}$ and D-MO with $35 \% \mathrm{v} / \mathrm{v} \mathrm{D}_{2} \mathrm{O}$ and at $25^{\circ} \mathrm{C}$, Figure $\mathrm{S3} .1(\mathrm{~A}, \mathrm{C})$, showed clear Bragg peaks for the gyroid cubic $Q_{\| 1}{ }^{G}$ phase with a lattice parameter (Ip) of $\sim 147 \AA$. The peak intensity for $\mathrm{H}-\mathrm{MO}$ in $\mathrm{D}_{2} \mathrm{O}$ was much higher than $\mathrm{D}-\mathrm{MO}$ in $\mathrm{D}_{2} \mathrm{O}$ as expected from the significantly higher contrast. The scattering intensity for D-MO in $\mathrm{D}_{2} \mathrm{O}$ can be explained by the difference in SLD between D-MO, $6.83 \times 10^{-6}$ $\AA^{-2}$ (Table 1), and $\mathrm{D}_{2} \mathrm{O}, 6.37 \times 10^{-6} \AA^{-2}$. The $\mathrm{H}-\mathrm{MO}$ and $\mathrm{D}-\mathrm{MO}$ samples with $35 \% \mathrm{v} / \mathrm{v} \mathrm{D}_{2} \mathrm{O}$ were heated to 38 ${ }^{\circ} \mathrm{C}$ and formed a single diamond cubic $Q_{\| 1}{ }^{\mathrm{D}}$ phase (without excess water, $1 \mathrm{p} \sim 89 \AA$ ) under these conditions. The first Bragg peak of the $Q_{\| 1}{ }^{D}$ phases show similar intensity to the respective $Q_{\| 1}{ }^{G}$ phases at $25{ }^{\circ} \mathrm{C}$; confirming that the scattering intensity was not strongly dependent on the cubic phase symmetry. However, a reduction in hydration of the diamond cubic $Q_{11}{ }^{D}$ phases upon heating was found to significantly affect the scattering intensity. Heating to $73^{\circ} \mathrm{C}$ and reduction to $\sim 27 \% \mathrm{v} / \mathrm{v}$ hydration $(\mathrm{Ip} \sim 74 \AA$ ) resulted in a scattering intensity three to five times lower than that observed at $25^{\circ} \mathrm{C}$ for $\mathrm{H}-\mathrm{MO}$ in $\mathrm{D}_{2} \mathrm{O}$ and D-MO in $\mathrm{D}_{2} \mathrm{O}$, respectively. For $\mathrm{H}-\mathrm{MO}$ in $\mathrm{H}_{2} \mathrm{O}$, Figure $\mathrm{S} 3.1(\mathrm{~B})$, the scattering intensity of the diamond cubic $\mathrm{Q}_{11}{ }^{\mathrm{D}}$ phase disappeared almost completely upon heating. Relative solvent, head and tail group SLD's which explain these results are shown in Table 1 and discussed in the Results and Discussion section.

(A) $\mathrm{H}-\mathrm{MO}, \mathrm{D}_{2} \mathrm{O}$

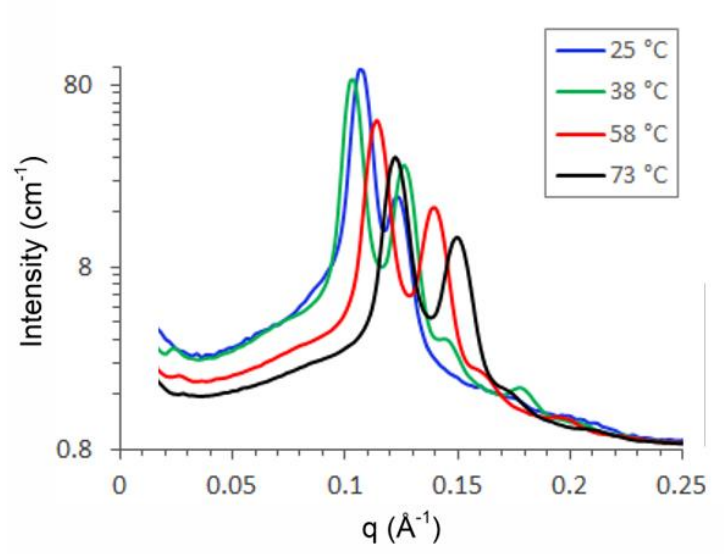

(B) $\mathrm{H}-\mathrm{MO}, \mathrm{H}_{2} \mathrm{O}(\mathrm{xs})$

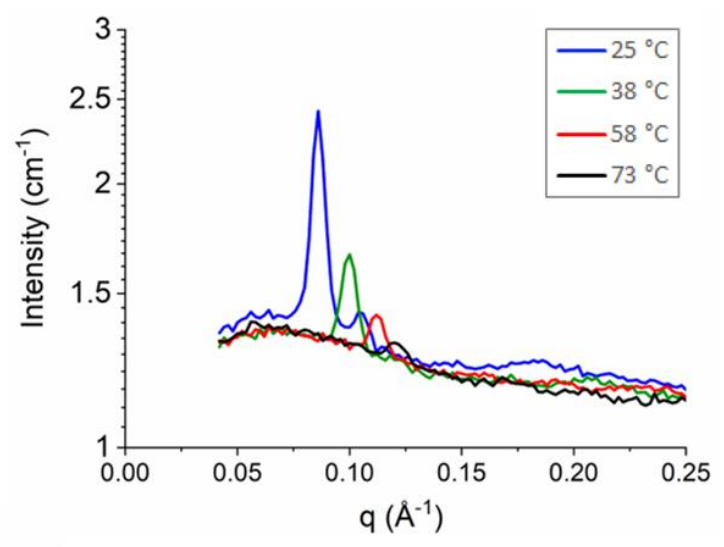

(C) D-MO, $\mathrm{D}_{2} \mathrm{O}$

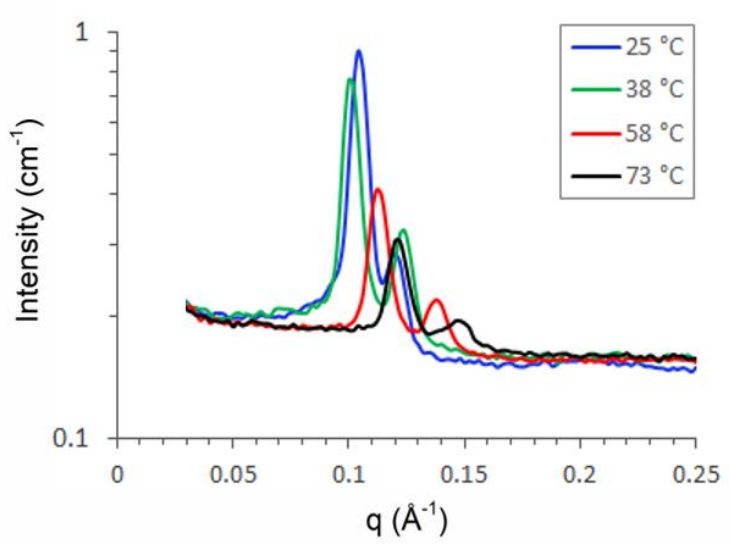

Figure S3.1. SANS data with the intensity shown on an absolute intensity scale. (A) H-MO and (C) D-MO prepared at $35 \%$ v/v $\mathrm{D}_{2} \mathrm{O}$ : gyroid cubic $Q_{11}{ }^{G}$ phases at $25^{\circ} \mathrm{C}$ and diamond $Q_{11}{ }^{D}$ cubic phases at $38-72{ }^{\circ} \mathrm{C}$. (B) diamond $Q_{11}{ }^{D}$ cubic phases of $\mathrm{H}-\mathrm{MO}$ with excess $\mathrm{H}_{2} \mathrm{O}$ and measured at $25^{\circ} \mathrm{C}-72^{\circ} \mathrm{C}$. 


\section{Supporting Information 4. Calculations for protein concentrations.}

Results are shown for $\mathrm{H}-\mathrm{MO}$ and $\mathrm{H}_{2} \mathrm{O}$ but the results for $\mathrm{D}-\mathrm{MO}$ and with $\mathrm{D}_{2} \mathrm{O}$ are identical.

Molecular volume H/D-MO:

$(S 4.1) v_{m}=\frac{\frac{M w\left(\mathrm{~g} \mathrm{~mol}^{-1}\right)}{\rho\left(\mathrm{g} \mathrm{nm}^{-3}\right)}}{N_{A}\left(\mathrm{~mol}^{-1}\right)}=\frac{\frac{356.54}{0.94 \times 10^{21}}}{6.023 \times 10^{23}}=0.630 \mathrm{~nm}^{3}$ molecule $^{-1}$

Unit cell volume $Q_{11}^{\mathrm{D}}$ (/p is lattice parameter):

$(S 4.2) v_{u c}=l p^{3}=10.5^{3}=1157.6 \mathrm{~nm}^{3}$

Lipid volume in $\mathrm{Q}_{11}{ }^{\mathrm{D}}$ at $40 \% \mathrm{w} / \mathrm{w}(38.6 \% \mathrm{v} / \mathrm{v})$ water:

$(S 4.3) v_{u c l}=v_{u c} \times 61.4 \%=1157.6 \times 0.614=711.1 \mathrm{~nm}^{3}$

Number of $\mathrm{MO}$ molecules per unit cell $\mathrm{Q}_{\| 1}{ }^{G}$ :

$(S 4.4) n_{m o l / u c}=\frac{v_{u c l}\left(\mathrm{~nm}^{3}\right)}{v_{m}\left(\mathrm{~nm}^{3} \text { molecule }^{-1}\right)}=\frac{711.1}{0.630}=1129$

Number of $\mathrm{MO}$ molecules per flat point $\mathrm{Q}_{11}{ }^{\mathrm{D}}$ :

(S4.5) $n_{\text {mol } / f p}=\frac{n_{\text {mol } / u c}}{4 \text { flat points }}=\frac{1129}{4}=282$

gA concentration (mol \%) with 1 transmembrane domain, consisting of two gA molecules per flat point:

$(S 4.6)[g A$, monomer $]=\frac{2}{n_{m o l / f p}}=\frac{2}{282} \times 100 \%=0.71 \mathrm{~mol} \%$

Distance between two flat points on the $\mathrm{Q}_{11}{ }^{\mathrm{D}}$ minimal surface:

(S4.7) [distance between flat points] $=\frac{l p}{\sqrt{2}}=\frac{10.5}{\sqrt{2}}=7.4 \mathrm{~nm}$

The diameter of two gA molecules including the side chains is approximately between 1.5 to $0.6 \mathrm{~nm}$ (with and without taking account of the side chains), and thus placing one transmembrane domain on each flat point should geometrically be well suited. 


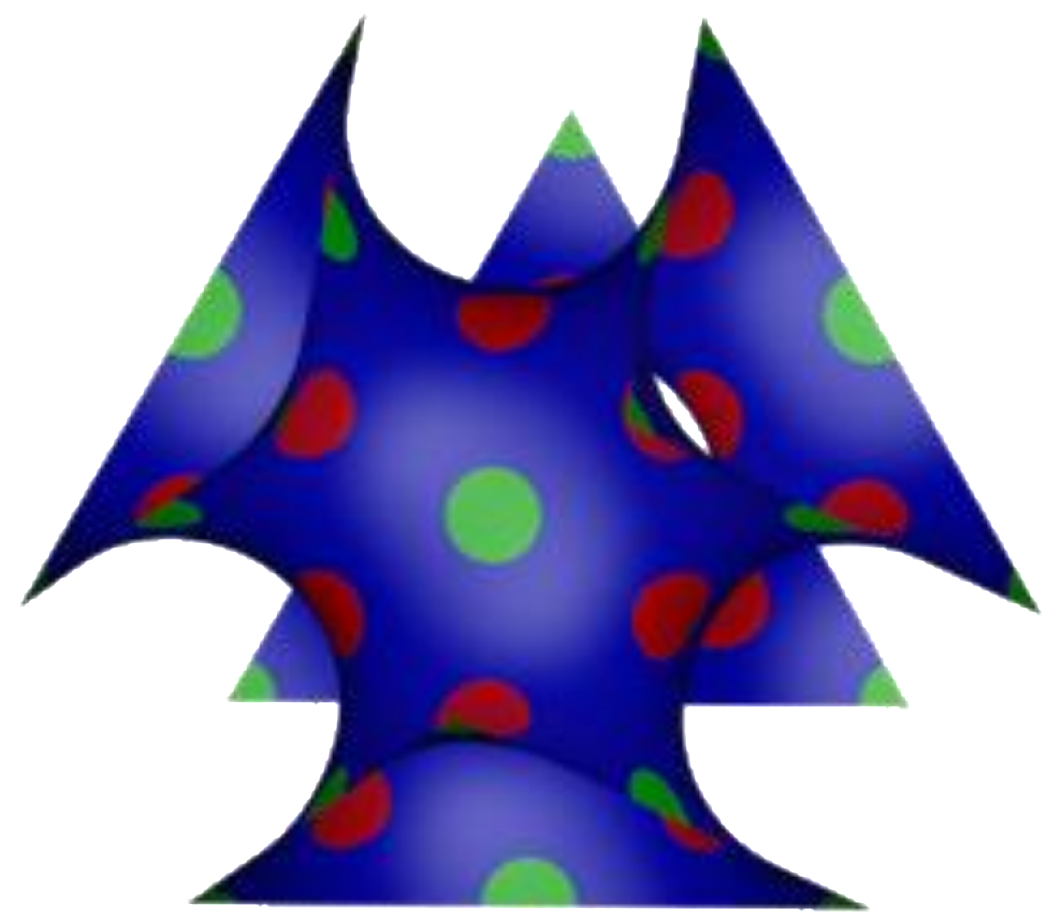

Figure S4.1. Diamond cubic $Q_{11} \mathrm{D}$ phase unit cell (for $\mathrm{MO}$, lattice parameter at $40 \% \mathrm{v} / \mathrm{v}$ hydration $\sim 10.5 \mathrm{~nm}$ ) with local flat points and points of highest Gaussian curvature indicated in green and red, respectively. 


\section{Supporting Information 5: Predicted small-angle scattering patterns of DAP12 and GpA crystal structures.}

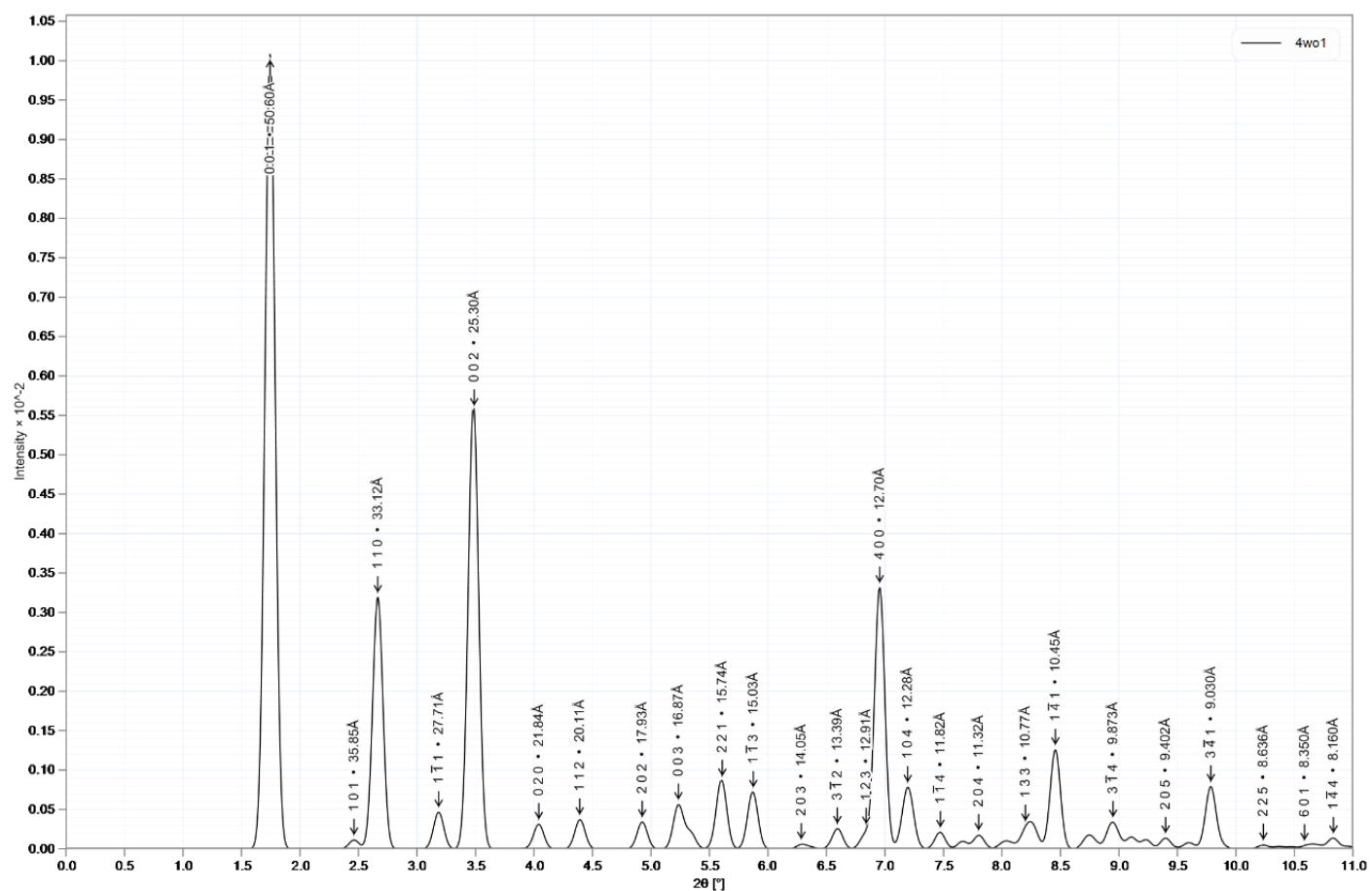

Figure S5.1. Predicted small-angle scattering pattern of DAP12 crystal structure (PDB ID 4WO1) obtained using CrystalDiffract. The main reflections observed are the $001\left(50.60 \AA\right.$, d-spacing $\left.0.124 \AA^{-1}\right), 110\left(33.12 \AA\right.$, d-spacing $\left.0.190 \AA^{-1}\right), 002(25.30 \AA$, d-spacing $\left.0.248 \AA^{-1}\right)$ and $400\left(12.70 \AA\right.$, d-spacing $\left.0.495 \AA^{-1}\right)$ planes.

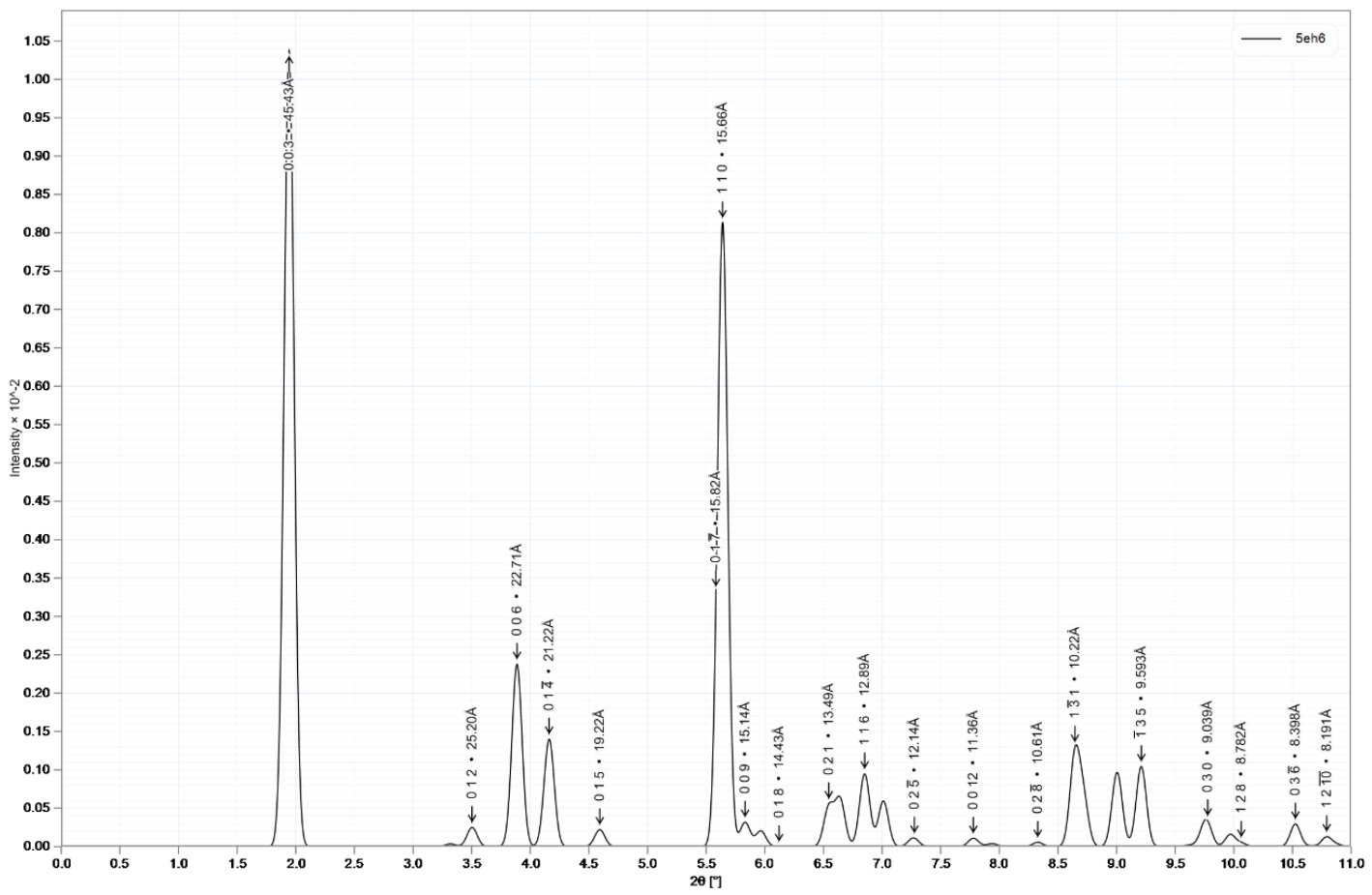

Figure S5.2. Predicted small-angle scattering pattern of GpA crystal structure (PDB ID 5EH6) obtained using CrystalDiffract. The main reflections observed are the $003\left(45.43 \AA\right.$, d-spacing $\left.0.138 \AA^{-1}\right), 006\left(22.71 \AA\right.$, d-spacing $\left.0.277 \AA^{-1}\right), 110(15.66 \AA$, d-spacing $\left.0.401 \AA^{-1}\right)$ and $121\left(10.22 \AA\right.$, d-spacing $\left.0.615 \AA^{-1}\right)$ planes. 


\section{Supporting Information 6: DAP12 crystallization in SANS cell and SAXS/SANS plots.}

(A) DAP12 crystals - 1

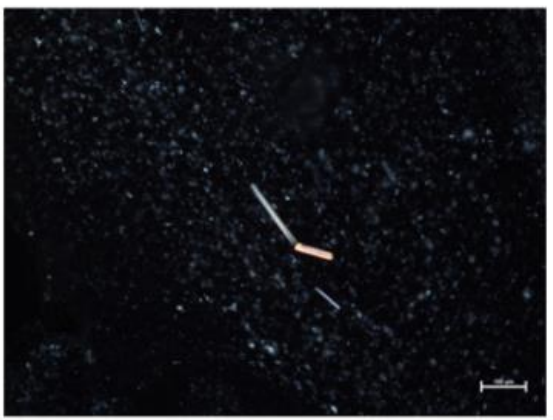

(B) DAP12 crystals - 2

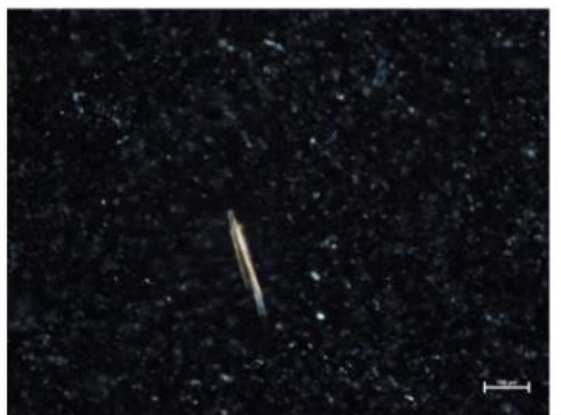

Figure S6.1. DAP12 crystal growth in the SANS sample is shown ten days after addition of the crystallization screen, obtained using a microscope with crossed-polarizers. The scale bars are $100 \mu \mathrm{m}$. Due to the precipitated peptide imaging in the SANS cells was difficult and images shown are from the sample taken out of the SANS cell and placed on a microscope slide.

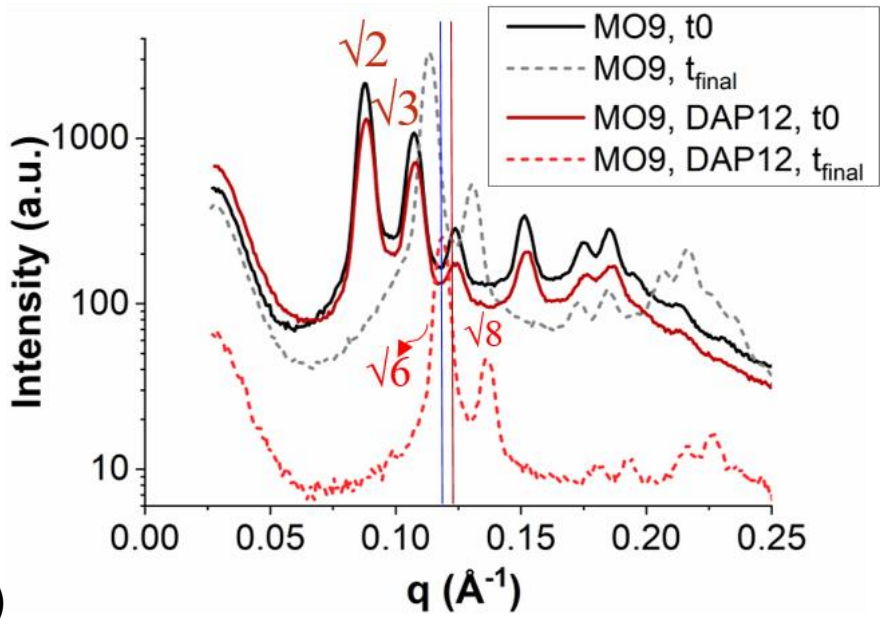

(A)

$q\left(\AA^{-1}\right)$

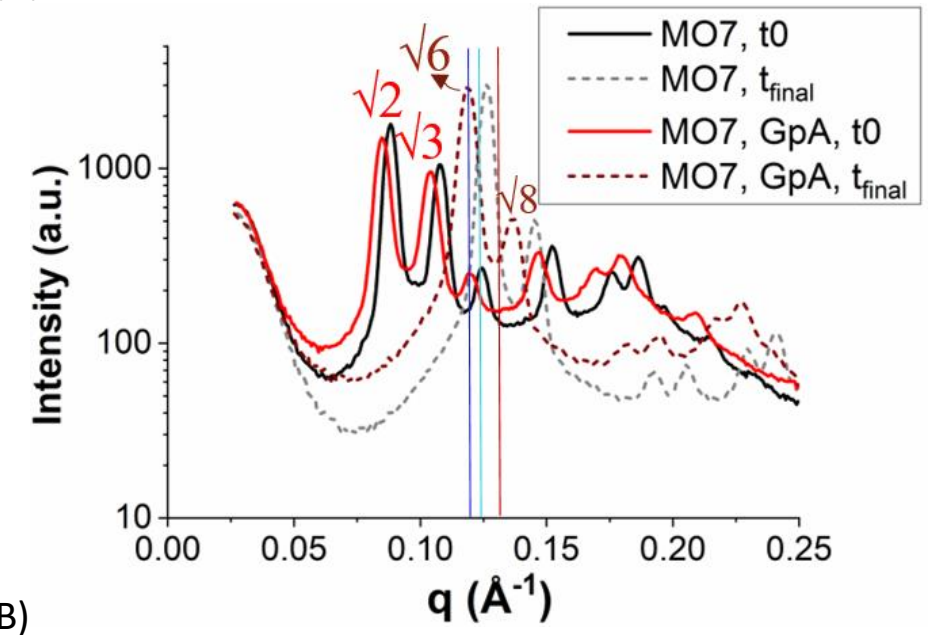

Figure S6.2. Complementary SAXS data of (A) MO9, DAP12 samples as shown in Figure 6(D) and (B) MO7, GpA samples as shown in Figure 8(D). 
(A) SANS M-MO9

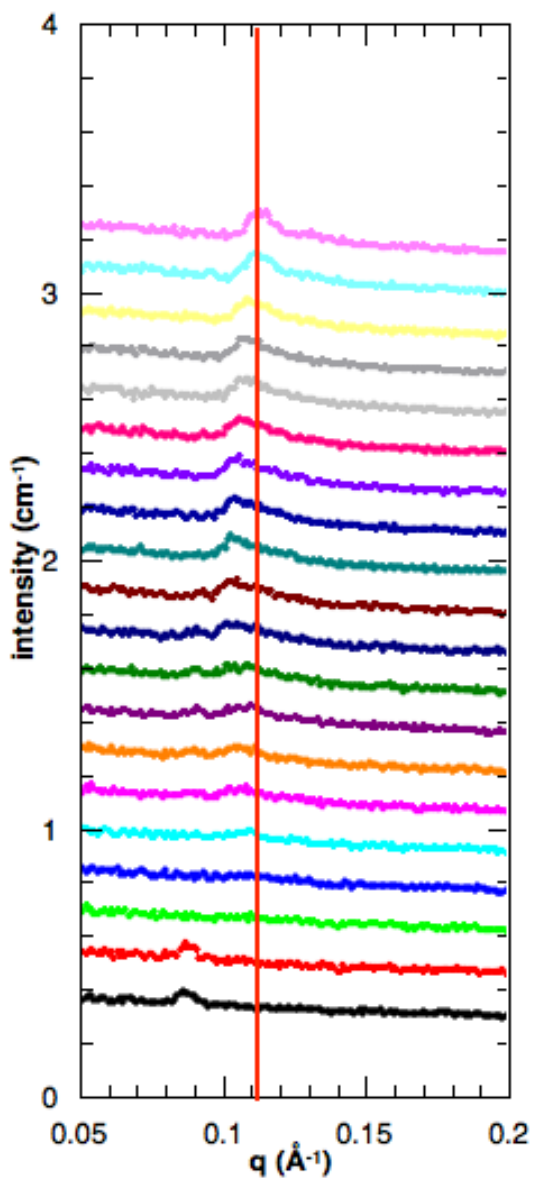

(B) SANS M-M09, DAP12

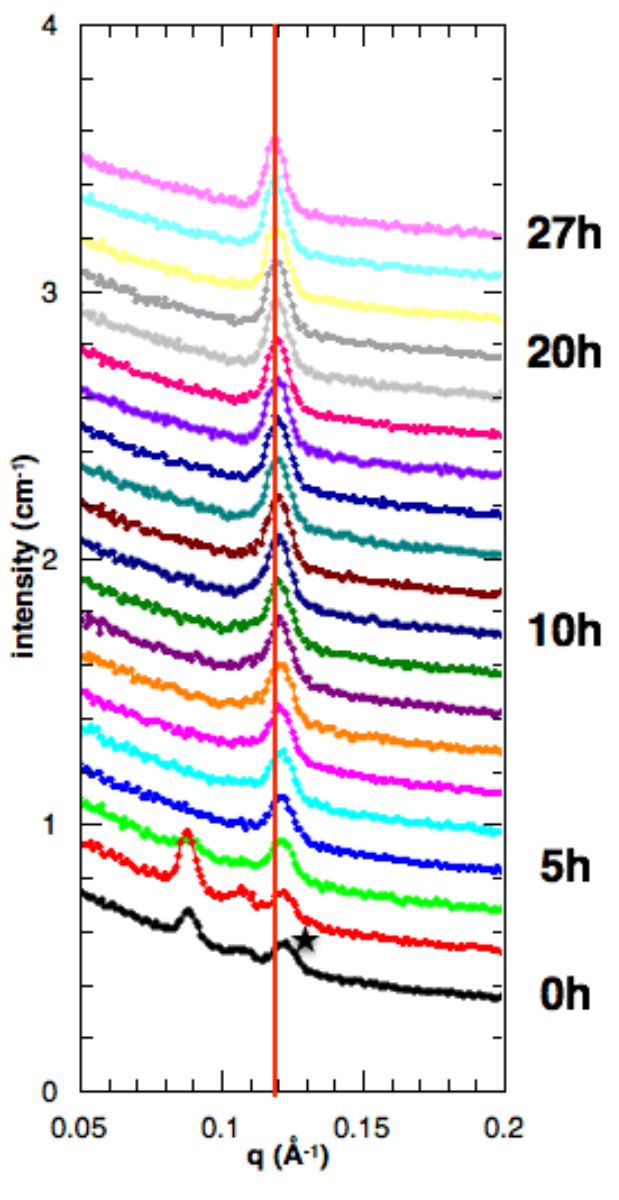

Figure S6.3. Re-plotted SANS data of Figure 6. (A) In the sample without peptide, the first gyroid peak appears at about $5 \mathrm{~h}$ and is small and broad at the start. With time, it moves systematically to higher q-values, which is expected due to dehydration. In the sample with peptide in (B), on the other hand, there is already a peak in this q-region present at the start $\left(q=0.123 \AA^{-1}\right)$, marked with an asterisk. With time, it appears to move to lower q-values, which is inconsistent with the expected trend due to dehydration. The red line denotes the q-value of the final gyroid peak position. 

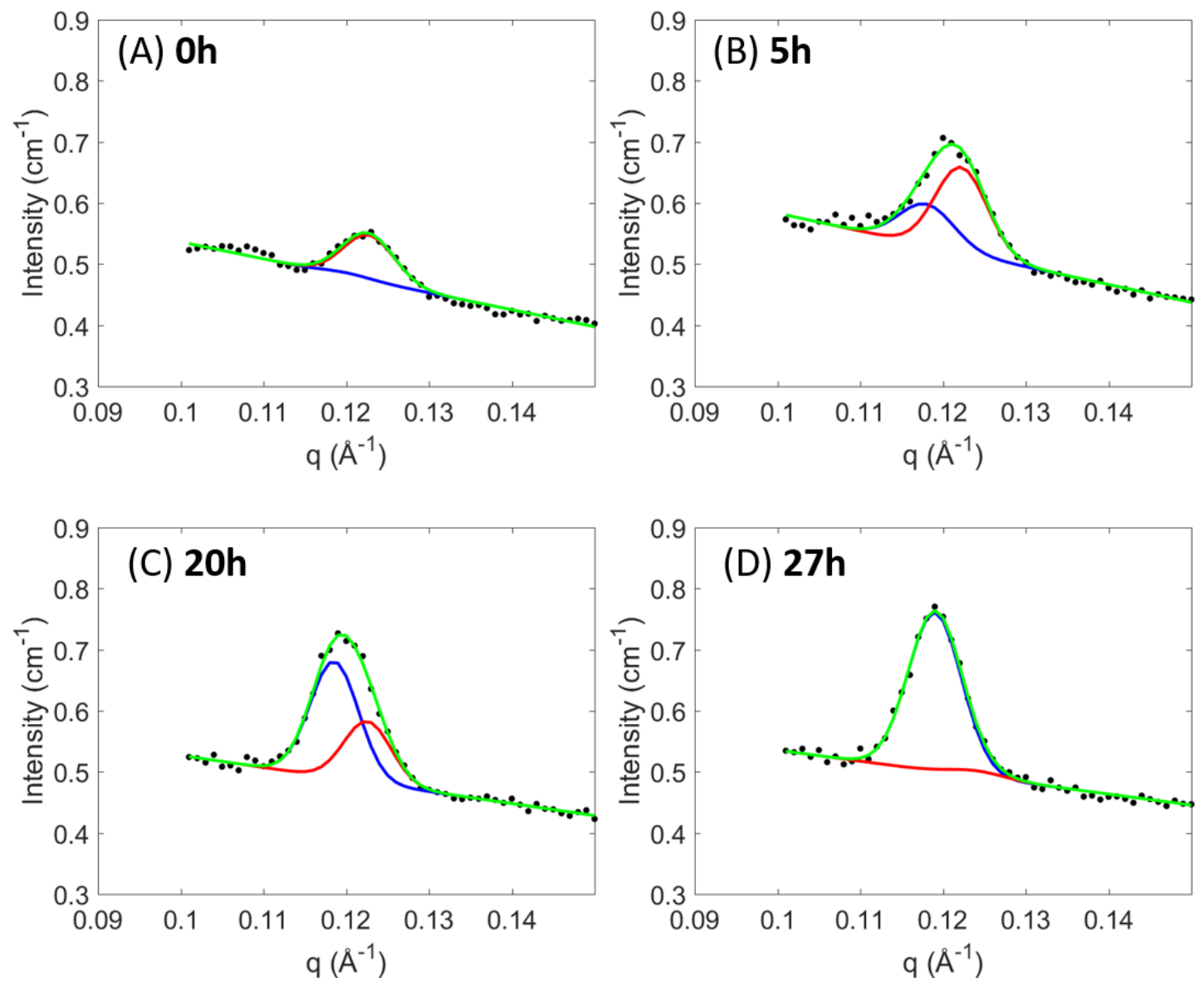

Figure S6.4. Simultaneous fitting of the MO9 DAP12 data as shown in Figure 6 at (A) 0 hours, (B) 5 hours, (C) 20 hours and (D) 27 hours with two Gaussians using the non-linear least squares method in MATLAB. ${ }^{19}$ It shows the relative contributions of the Gaussians at $0.119 \AA^{-1}$ in blue and $0.123 \AA^{-1}$ in red which represent the $Q_{11}{ }^{G}(\sqrt{ } 6)$ and $L_{\alpha} / L_{c}(*)$ phases, respectively. A linear line was used as the background and the green line is the combined fit of the data shown in the black dots. The two peak positions were fixed within $0.002 \AA^{-1}$ in the fitting. The fitting confirms that at 0 and 5 hours there is a significant contribution from the $L_{\alpha} / L_{c}$ phase while after longer times the peak can be fit with the $Q_{11}{ }^{G}$ phase only.

Table S6.1. Peak intensity, position and width for each of the fitted Gaussians as shown in Figure S6.4. For 0 hours (h) the contribution of Gaussian 1 (shown in blue in the plots) is negligible, and for 27h the contribution of Gaussian 2 (shown in red in the plots) is negligible as indicated with values in italic and grey. The peak position of the $Q_{\| 1}{ }^{G}$ phase (Gaussian 1 ) moves to higher q-values due to the dehydration by PEG, while the intensity of the $L_{\alpha} / L_{c}$ phase (Gaussian 2 ) increases in intensity in the first 5 hours, and then decreases from 5-27 hours, as shown in bold.

\begin{tabular}{|l|c|c|c|c|c|c|}
\hline \multicolumn{3}{|c|}{ Gaussian 1 } & \multicolumn{3}{c|}{ Gaussian 2 } \\
\hline & Intensity & Position & Width & Intensity & Position & Width \\
\hline Oh & 0.0050 & 0.1200 & 0.0029 & $\mathbf{0 . 0 7 4 6}$ & 0.1227 & 0.0031 \\
\hline 5h & 0.0675 & $\mathbf{0 . 1 1 8 0}$ & 0.0033 & $\mathbf{0 . 1 4 0 2}$ & 0.1222 & 0.0031 \\
\hline 20h & 0.1908 & $\mathbf{0 . 1 1 8 6}$ & 0.0029 & $\mathbf{0 . 1 0 0 4}$ & 0.1226 & 0.0029 \\
\hline 27h & 0.2600 & $\mathbf{0 . 1 1 9 0}$ & 0.0032 & 0.0096 & 0.1240 & 0.0033 \\
\hline
\end{tabular}




\section{Supporting Information 7: SANS scattering intensity lamellar $L_{\alpha}$ phase of M-MO7.}

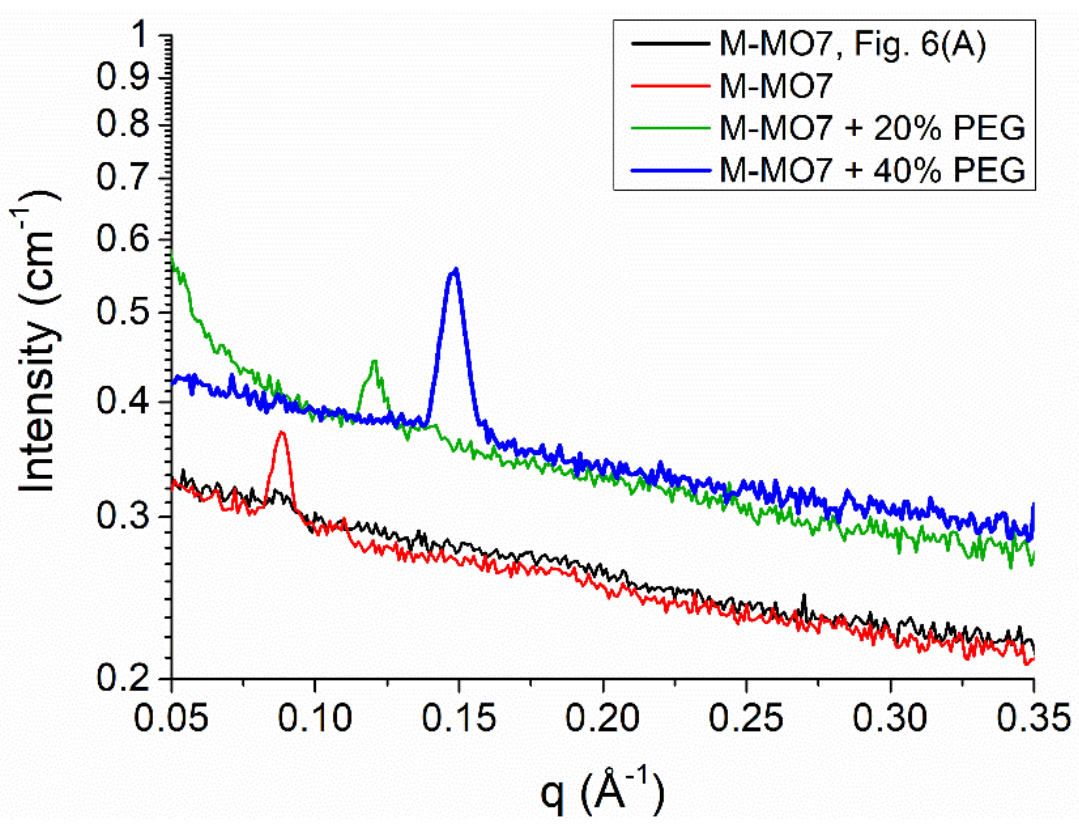

(A)

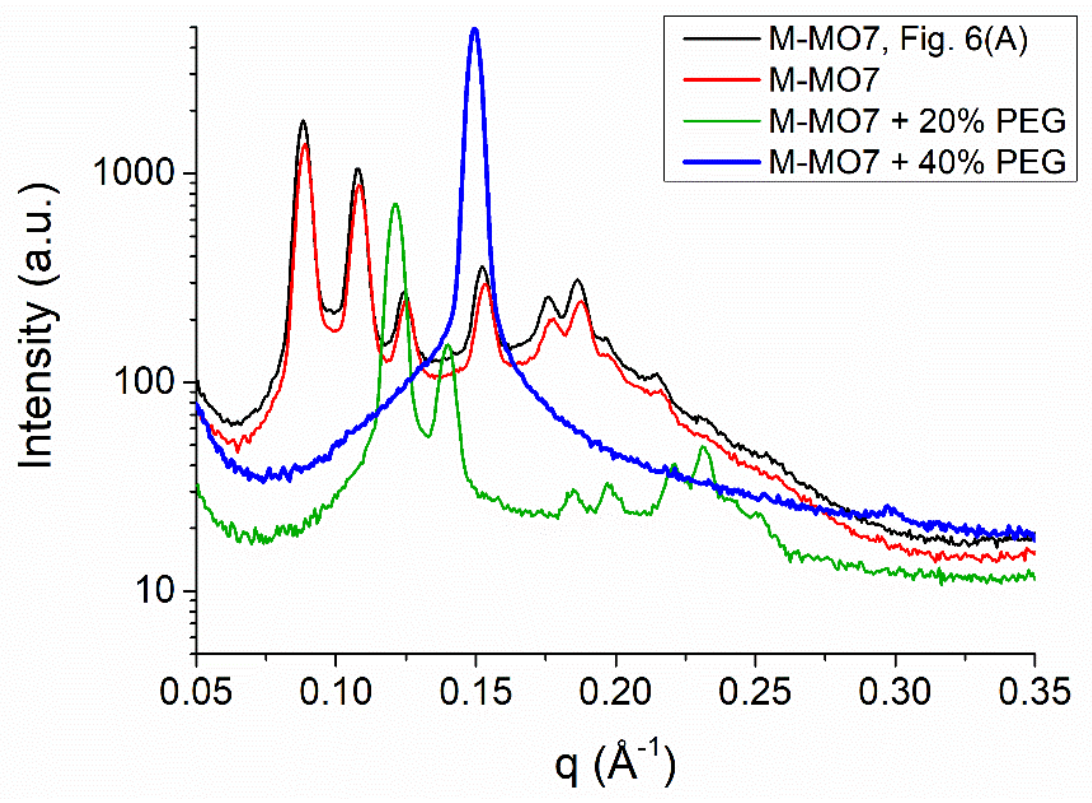

Figure S7.1. (A) SANS scattering intensity on an absolute intensity scale and (B) complementary SAXS analysis on an arbitrary intensity scale showing fluid lamellar $L_{\alpha}$ phase scattering for a sample with 7\% w/w H-MO with 93\% w/w D-MO (M-MO7). The lamellar $L_{\alpha}$ phase formation was induced by addition of $40 \% \mathrm{w} / \mathrm{v}$ PEG $4000 \mathrm{~g} \mathrm{~mol}^{-1}$ in $\mathrm{D}_{2} \mathrm{O}$ (SLD $\left.6.37 \times 10^{-6} \AA^{-2}\right)$. The scattering patterns shown in blue are after 24 hours when the phase transition was complete. The PEG solution ( $500 \mu \mathrm{L})$ was added into the SANS cell to replace the crystallization screen with $20 \% \mathrm{w} / \mathrm{v}$ PEG $4000 \mathrm{~g} \mathrm{~mol}^{-1}$ which was from a screen with $0.05 \mathrm{M} \mathrm{CaCl}_{2}$ and 0.1 $\mathrm{M}$ bis-tris propane ( $\mathrm{pH} 6.4$, SLD $6.25 \times 10^{-6} \AA^{-2}$ ). The scattering pattern shown (green curves) was after four days when the peak position (representative of the $Q_{11}{ }^{G}$ lattice parameter) did not move anymore. 


\section{Supporting Information 8: DAP12 crystallization from M-M07.}

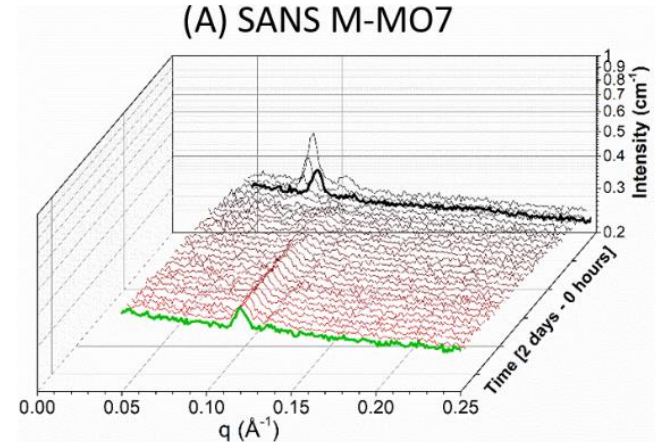

(C) SANS $t_{0}, t_{\text {final }}$

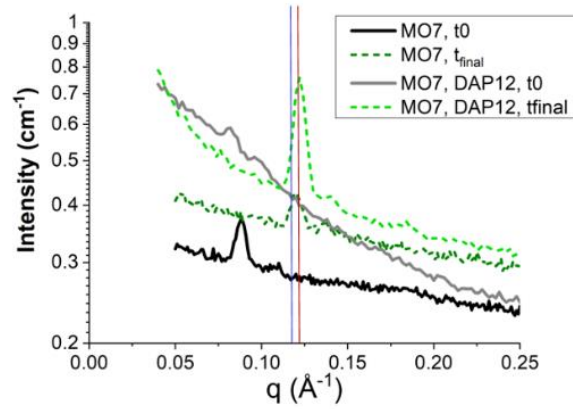

(E) SANS Intensities vs. time

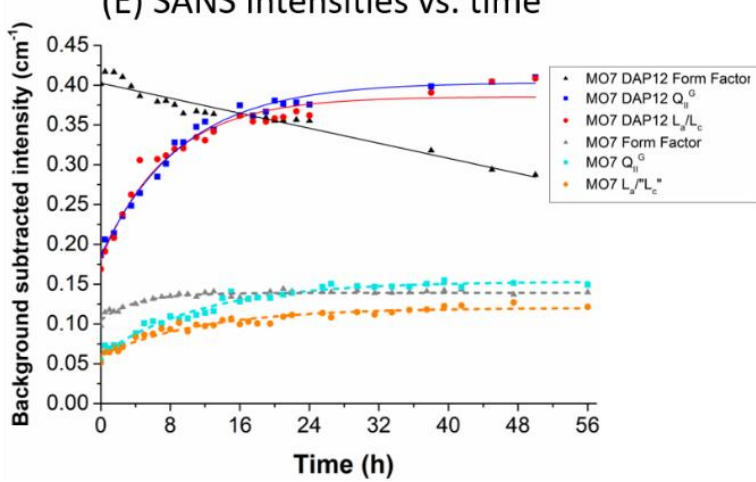

Microscopy $12 \mathrm{~h}$ (left), 70h (right)
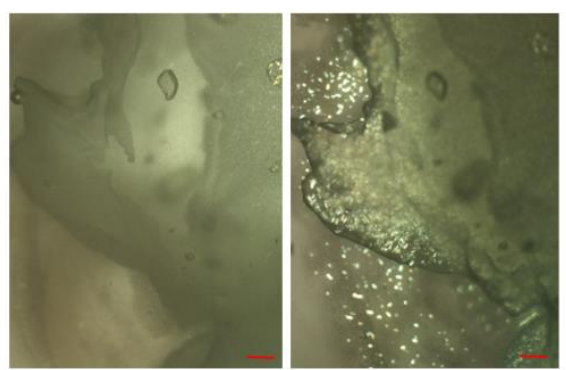

Figure S8.1. DAP12 crystallization from the contrast-matched cubic phase with $7 \% \mathrm{H}-\mathrm{MO}$ and $93 \% \mathrm{D}-\mathrm{MO}$ (M-MO7), at 5.5\% w/w DAP12 with respect to the lipid $\left(0.7 \mathrm{~mol} \%\right.$ and $35 \mathrm{mg} \mathrm{mL}^{-1}$ in the cubic phase at the start) and at $20^{\circ} \mathrm{C}$. SANS data with the intensity shown on an absolute intensity scale in (A-D) show changes in time upon addition of crystallization screen $A\left(S L D 6.21 \times 10^{-6} \AA^{-2}\right)$. The cubic phase samples were prepared with $\mathrm{D}_{2} \mathrm{O}$ (SLD $\left.6.37 \times 10^{-6} \AA^{-2}\right)$. Time-evolution is shown for samples without (A) and with (B) peptide. SANS exposure for each time point was 30 minutes. In the plot the time evolution is shown with a black to red color gradient from the back to the front and the first (t0, black) and final time points ( $\mathrm{t}_{\text {final, }}$, green) are shown in bold. In (C) data before addition of the screen and final time points for both samples are shown in one plot for a direct comparison and in (D) the SANS data with the DAP12 peptide is shown with a narrower q-range and ormation of the fluid lamellar $L_{\alpha} /$ lamellar crystalline $L_{c}$ peak at $0.123-0.124 \AA^{-1}$ was clearly observed within the first eight hours of crystallization. In $(E)$ the background $\left(q=0.29-0.30 \AA^{-1}\right)$ subtracted intensities of the form factor $\left(q=0.05-0.06 \AA^{-1}\right), \sqrt{6}$ of the final gyroid cubic $Q_{11}{ }^{6}$ phase $\left(q=0.119-0.120 \AA^{-1}\right)$ and the fluid lamellar $L_{\alpha}$ / lamellar crystalline $L_{c}$ phase $\left(q=0.123-0.124 \AA^{-1}\right.$, indicated as $\left.{ }^{*}\right)$ as a function of time are shown. The $q$-values of the latter two are also indicated with the vertical lines in (C-D). In (A-D) V2 and V3 indicate the Bragg reflections of the diamond cubic $Q_{\| 1}^{D}$ phase and $\sqrt{6}$ and $\sqrt{ } 8$ of the gyroid cubic $Q_{\| 1}{ }^{6}$ phase. In $(E)$ a linear or exponential fit of the data is shown as a guide for the eye. The intensities of the first seven hours cannot be taken into consideration due to solvent equilibration (see Supporting Information 8). Additionally, in this case case the final gyroid cubic $Q_{\| 1}{ }^{G}$ peak position is very close to spacing of the the fluid lamellar $L_{\alpha} /$ lamellar crystalline $L_{c}$ peak. For this reason, analysis of these intensities cannot be interpreted. In (F) microscopy showing the DAP12 crystallization is shown after 12 hours (left image) and 70 hours (right image). Scale bars are $200 \mu \mathrm{m}$. Crystals were visible throughout the SANS sample. 
Supporting Information 9: Solvent exchange for a cubic phase of $\mathrm{H}-\mathrm{MO}$ in $\mathrm{H}_{2} \mathrm{O}$ upon the addition of $\mathrm{D}_{2} \mathrm{O}$ over a period of 4 days.

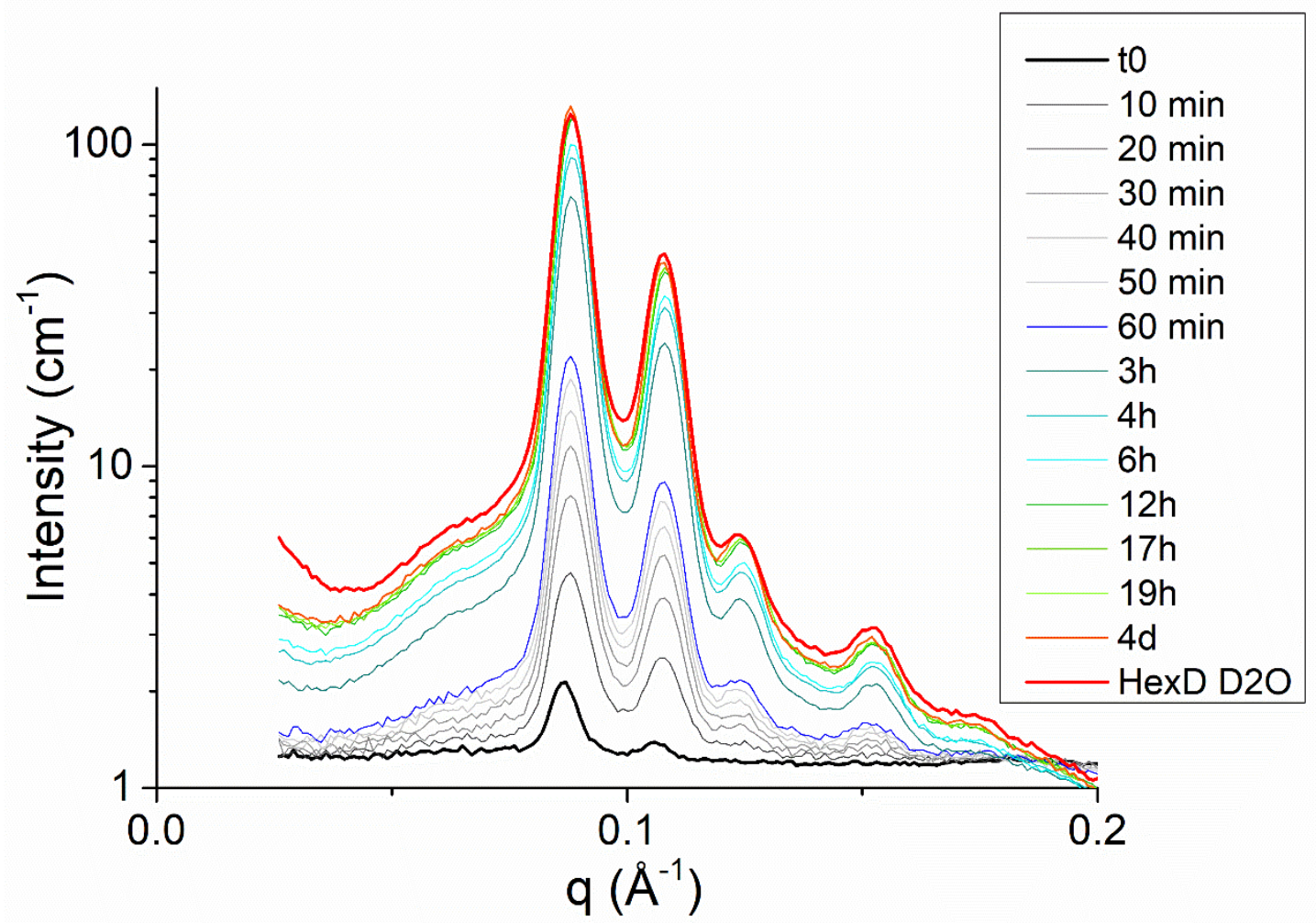

Figure S9.1. SANS data showing changes in scattering intensity of the diamond cubic $\mathrm{Q}_{\| 1} \mathrm{D}$ phase at $20^{\circ} \mathrm{C}$ on an absolute scale. At the start there was $100 \mu \mathrm{L} \mathrm{H}-\mathrm{MO}$ with excess $\mathrm{H}_{2} \mathrm{O}$, which was then surrounded by $500 \mu \mathrm{L} \mathrm{D}_{2} \mathrm{O}$ and intensity changes were followed over time. The intensity is compared to the scattering of a sample of $\mathrm{H}-\mathrm{MO}$ in which all exchangeable hydrogens were exchanged for deuteriums (HexD) with excess $\mathrm{D}_{2} \mathrm{O}$. 


\section{Supporting Information 10: Synchrotron SAXS data in meso crystallization GpA.}

\section{$25 \%$ w/v PEG $1500 \mathrm{~g} \mathrm{~mol}^{-1}$}
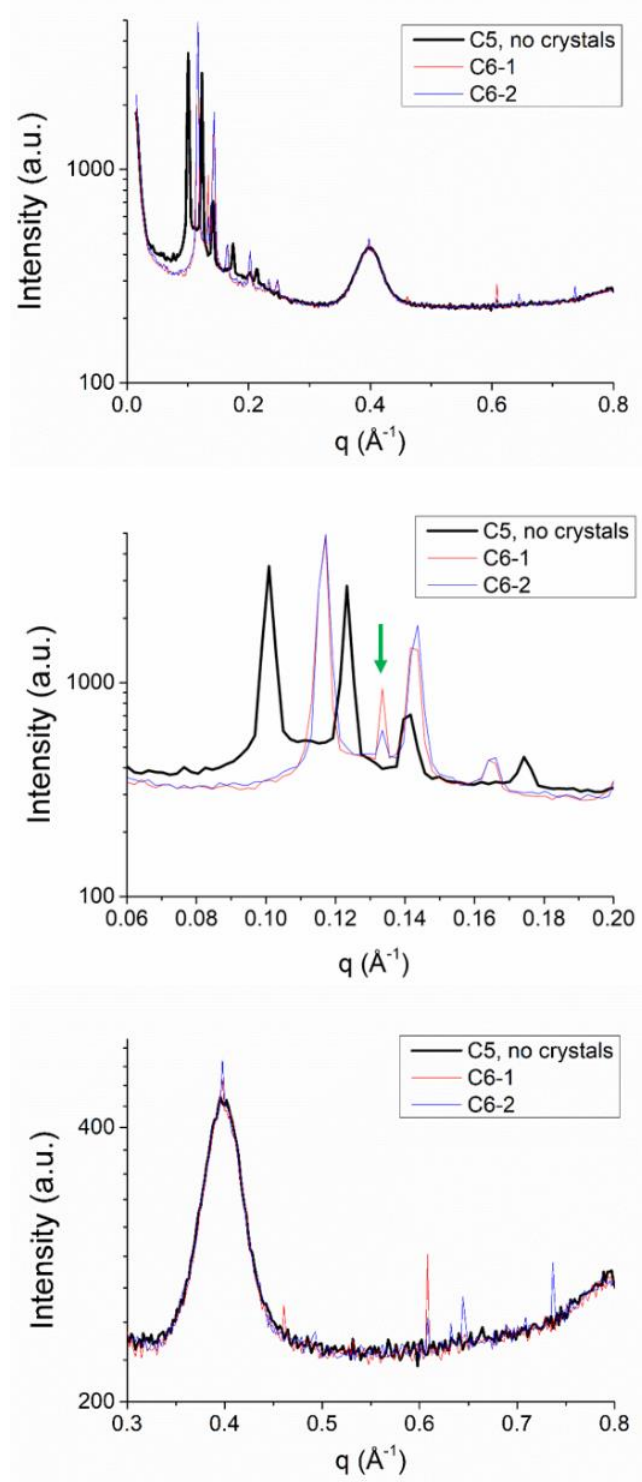

\section{$20 \% \mathrm{w} / \mathrm{v}$ PEG $6000 \mathrm{~g} \mathrm{~mol}^{-1}$}
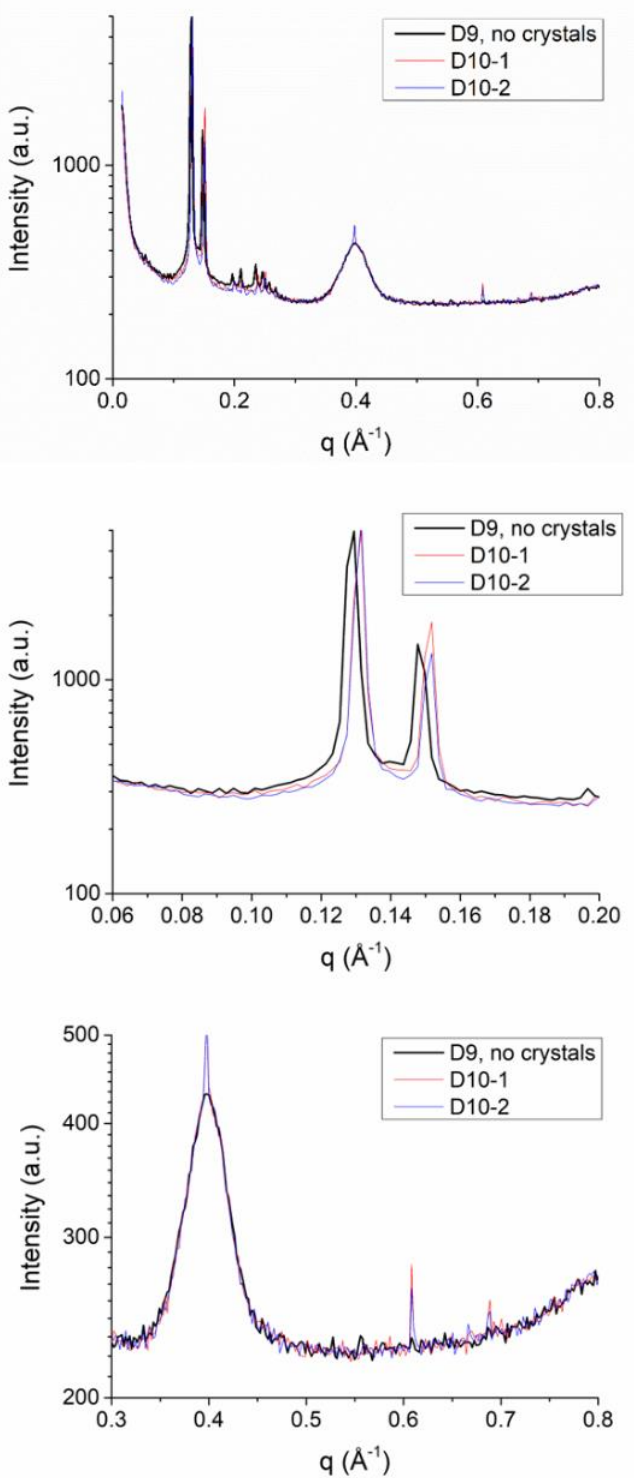

Figure S10.1. Synchrotron SAXS analysis of GpA crystallization conditions from the PACT screen, shot in situ 5 days after the plates were set up. Comparison of conditions with a final diamond cubic $Q_{\| 1}{ }^{D}$ phase (left column with $25 \% \mathrm{w} / \mathrm{v}$ PEG $1500 \mathrm{~g} \mathrm{~mol}^{-1}$ as the precipitant) and final gyroid cubic $Q_{\| 1}{ }^{G}$ phase (right column with $20 \% \mathrm{w} / \mathrm{v} \mathrm{PEG} 6000 \mathrm{~g} \mathrm{~mol}^{-1}$ as the precipitant). In all plots there is a comparison of wells that did not show crystallization (left column well C5: $25 \% \mathrm{w} / \mathrm{v}$ PEG $1500 \mathrm{~g} \mathrm{~mol}^{-1}$, 10\% v/v propionatecacodylate-bis tris propane ( $\mathrm{pH} 8)$, and right column well D9: $20 \% \mathrm{w} / \mathrm{v} \mathrm{PEG} 6000 \mathrm{~g} \mathrm{~mol}^{-1}, 0.2 \mathrm{M}$ lithium chloride, $0.1 \mathrm{M}$ tris chloride ( $\mathrm{pH} 8)$ ) and that did show GpA crystallization (left column well C6: 25\% w/v PEG $1500 \mathrm{~g} \mathrm{~mol}^{-1}, 10 \% \mathrm{v} / \mathrm{v}$ propionate-cacodylate-bis tris propane $\left(\mathrm{pH}\right.$ 9), and SANS conditions right column well D10: $20 \% \mathrm{w} / \mathrm{v}$ PEG $6000 \mathrm{~g} \mathrm{~mol}^{-1}, 0.2 \mathrm{M}$ magnesium chloride, $0.1 \mathrm{M}$ tris chloride $(\mathrm{pH} 8))$. Differences in the crystallization screen conditions that did and did not result in crystallizations are underlined ( $\mathrm{pH}$ and buffer salt). The top row shows the entire q-range, the middle row shows a narrow low q-range with the first three Bragg peaks of the cubic phases and the bottom row shows a narrow q-range at wide angles with the lamellar crystalline peaks at qvalues as predicted based on the crystal structure (see Supporting Information 4). The green arrow indicate the GpA crystal peak at $0.138 \AA^{-1}$. 
$\mathrm{C} 5[\mathrm{pH} 8]$, t0

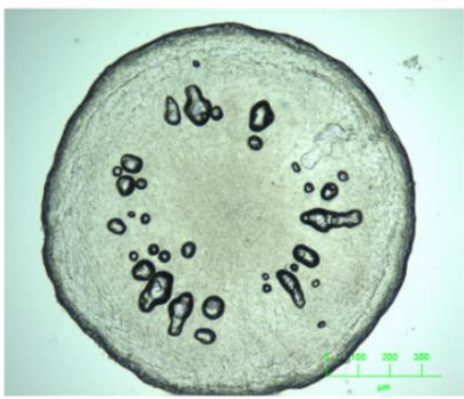

$\mathrm{C} 6[\mathrm{pH} 9]$, to

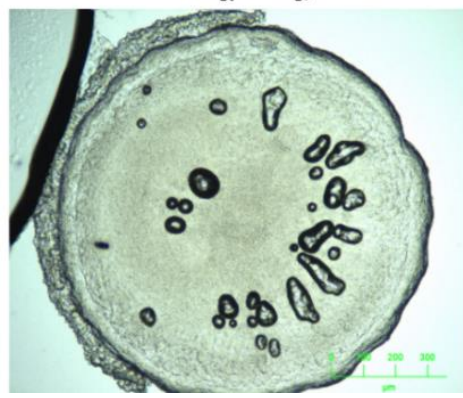

$\mathrm{C} 5[\mathrm{pH} 8], \mathrm{t} 4 \mathrm{~d}$

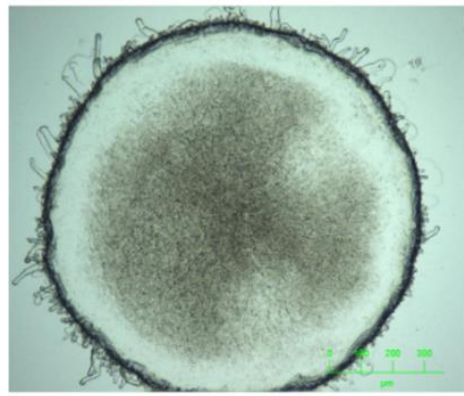

$\mathrm{C} 6[\mathrm{pH} 8], \mathrm{t} 4 \mathrm{~d}$

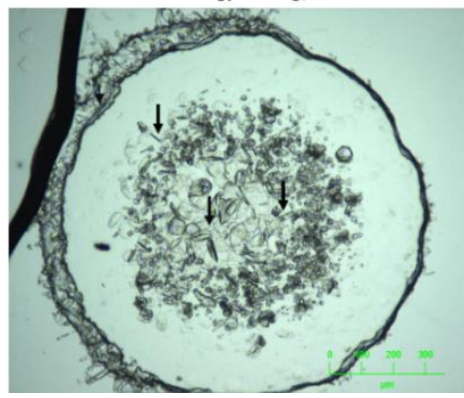

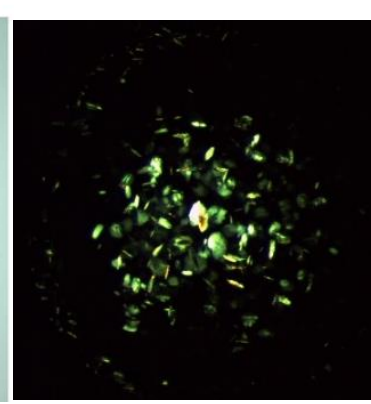

Figure S10.2. Images in meso crystallization drops for which the SAXS analysis is shown in Figure S5.1 in the left column (25\% w/v PEG $1500 \mathrm{~g} \mathrm{~mol}$ as precipitant and final diamond cubic $Q_{\| 1} \mathrm{D}$ phase). Images taken with the Minstrel HTUV imaging system immediately after setup of the crystallization drops (left column, to) and after 4 days (right column, $\mathrm{t} 4 \mathrm{~d}$ ) are shown. Black arrows indicate crystals as confirmed using crossed polarizers (far right). Top row, no crystals well C5: $25 \% \mathrm{w} / \mathrm{v}$ PEG $1500 \mathrm{~g} \mathrm{~mol} \mathrm{~m}^{-1}, 10 \% \mathrm{v} / \mathrm{v}$ propionate-cacodylate-bis tris propane ( $\mathrm{pH} 8$ ). Bottom row, with crystals well C6: $25 \% \mathrm{w} / \mathrm{v}$ PEG $1500 \mathrm{~g} \mathrm{~mol} \mathrm{l}^{-1}, 10 \% \mathrm{v} / \mathrm{v} \mathrm{propionate-}$ cacodylate-bis tris propane $(\underline{\mathrm{pH}}$ 9).
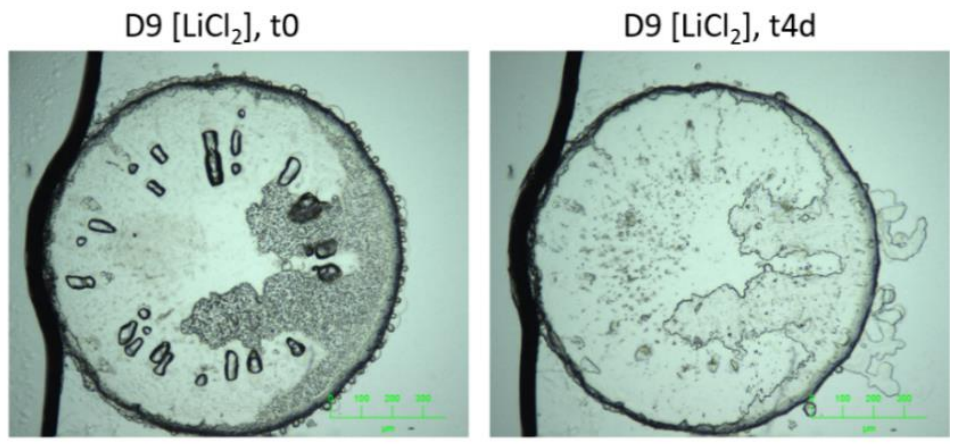

$\mathrm{D} 10\left[\mathrm{MgCl}_{2}\right]$, to
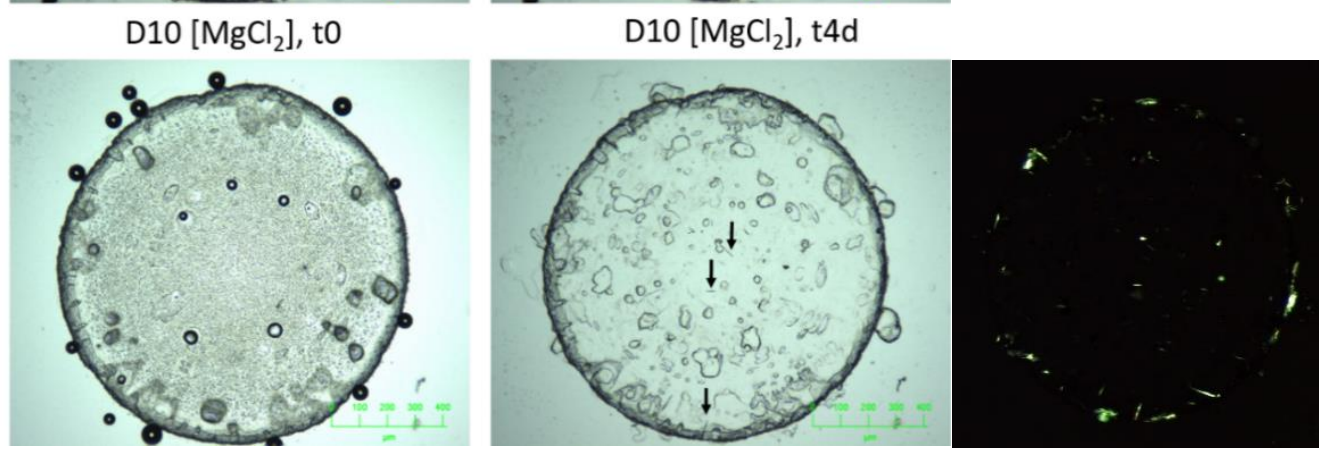

Figure S10.3. Images in meso crystallization drops for which the SAXS analysis is shown in Figure S5.1 in the right column (20\% w/v PEG $6000 \mathrm{~g} \mathrm{~mol}$ as precipitant and final gyroid cubic $Q_{11}{ }^{G}$ phase). Images taken with the Minstrel HTUV imaging system immediately after setup of the crystallization drops (left column, t0) and after 4 days (right column, $\mathrm{t} 4 \mathrm{~d}$ ) are shown. Black arrows indicate crystals as confirmed using crossed polarizers (far right). Top row, no crystals: D9: $20 \% \mathrm{w} / \mathrm{v} \mathrm{PEG} 6000 \mathrm{~g} \mathrm{~mol} \mathrm{~m}^{-1}, 0.2 \mathrm{M}$ lithium chloride, $0.1 \mathrm{M}$ tris chloride $\left(\mathrm{pH}\right.$ 8). Bottom row, with crystals well D10: $20 \% \mathrm{w} / \mathrm{v}$ PEG $6000 \mathrm{~g} \mathrm{~mol}{ }^{-1}, 0.2 \mathrm{M}^{\text {magnesium }}$ chloride, $0.1 \mathrm{M}$ tris chloride (pH 8). 